Canadian Journal of Fisheries and Aquatic Sciences 2006; 63(3) : 510-533

http://dx.doi.org/xxx

(c) 2006 NRC Research Press Electronic Journals

The original publication is available at http://pubs.nrc-cnrc.gc.ca
Archimer http://www.ifremer.fr/docelec/ Archive Institutionnelle de l'Ifremer

\title{
Improving the definition of fishing effort for important European fleets by accounting for the skipper effect
}

\author{
Paul Marchal ${ }^{1 *}$, Bo Andersen ${ }^{2}$, David Bromley ${ }^{3}$, Ane Iriondo ${ }^{4}$, Stéphanie Mahévas ${ }^{1}$, \\ Floor Quirijns ${ }^{5}$, Brian Rackham ${ }^{3}$, Marina Santurtún ${ }^{4}$, Nicola Tien $^{5}$ and Clara Ulrich ${ }^{2}$
}

\author{
${ }^{1}$ Paul Marchal, IFREMER, 150 Quai Gambetta, BP 699, 62321 Boulogne s/mer, France. \\ ${ }^{2}$ DIFRES, Charlottenlund Castle, 2900 Charlottenlund, Denmark. \\ ${ }^{3}$ CEFAS, Pakefield Road, NR330HT Lowestoft, United Kingdom. \\ ${ }^{4}$ AZTI, Fisheries Resources Department, Txatxarramendi Ugarte, Z/G, 48395 Sukarrieta, Spain. \\ ${ }^{1}$ Stéphanie Mahévas. IFREMER, Rue de l'lle d'Yeu, BP 21105, 44311 Nantes Cedex 03, France. \\ ${ }^{5}$ RIVO, Department of Biology and Ecology, PO Box 68, Haringkade 1, 1970 AB, IJmuiden, The Netherlands.
}

*: Corresponding author : paul.marchal@ifremer.fr)

\begin{abstract}
The scope of this paper is to quantify, for a wide selection of European fisheries, fishing tactics and strategies and to evaluate the benefits of adjusting the definition of fishing effort using these elements. Fishing tactics and strategies were identified by métiers choices and a series of indices. These indices have been derived to reflect shifts in tactics (within a fishing trip) and in strategies (within a year). The Shannon-Wiener spatial diversity indices of fishing tactics (FT_SW) and strategies (YE SW) had the greatest impact on catch rates. In particular, FT SW was always negatively correlated to catch rates. One may anticipate that during a fishing trip, vessels with high FT_SW have been searching fish aggregations for a long time, while vessels with low FT_SW have been more efficient in finding these aggregations. The linkage between YE SW and catch rates was of a more complex nature. Adjusting fishing effort by means of (i) the métier effect and (ii) the indices of tactics and strategies generally led to a substantial gain in the precision of the relationship between fishing mortality and fishing effort.
\end{abstract}

Keywords: skipper effect, GLM modeling, catch rates, fishing mortality, fishing effort 


\section{Introduction}

A common concern of fisheries managers is to be able to reconcile the objectives of maintaining fisheries profit whilst safeguarding the fish resources, especially when these are exploited beyond biological safe limits. In the European Union (EU) waters, the management of fisheries and fish resources has been adversely altered by, (i) the lack of consensus on management targets and strategies and also, (ii) the poor understanding of the links between management tools, fleet developments and the pressure exerted on fishing communities. A major long-going issue, relevant to both (i) and (ii) is the exploration of the relationship between fishing mortality (F) and fishing effort (E). A common assumption underlying fish stock assessments and fisheries management is that fishing mortality (F) is directly proportional to fishing effort (E):

$\mathrm{F}(\mathrm{t})=\mathrm{qE}$, where $\mathrm{q}$ is referred to as the catchability coefficient.

However, it has been ascertained in a number of fisheries studies that the relationship between fishing mortality and effort could be of a more complex nature, as a result of combined mechanisms including changes in fish accessibility (Swain et al. 1994), technical creeping (Mahévas et al. 2004) and shifts in fishing regimes (Pascoe et al. 2001).

Defining effort such that fluctuations in effort can be related to fluctuations in fishing mortality would positively impact, the reliability of catch rates as stock abundance indicators, the precision of stock assessments tuned by these catch rates and eventually the scientific basis for managers decision-making (Cook and Armstrong 1985; Arreguin-Sanchez 1996; Marchal et al. 2003). In addition, defining effort such that the correlation between fishing mortality and fishing effort increases would allow fisheries managers to evaluate the impact of effort-based management regimes on the pressure really exerted on fish stocks (Overholtz et al. 1995; Ulrich et al. 2002). The reliability of the relationship between F and fishing effort 
depends on the precision of both the measurement of fishing effort and the estimate of fishing mortality. This paper examines the issue of better measuring fishing effort.

Fishing effort is traditionally estimated by combining available measurements of fishing capacity (fixed production inputs) and of fishing activity (variable production inputs). Fishing capacity is frequently approached by some attribute of the operating vessel (vessel length, engine power, gross tonnage) (Gulland 1964; Robson 1966; Marchal et al. 2002), but a number of investigations have been carried out to incorporate other elements, including gear technology and equipment on-board, in the definition of fishing effort (Hovgaard 1996; Rose and Nunnallee 1998; Sangster and Breen 1998). Fishing activity is typically estimated by the time spent fishing during a fishing trip. Such a definition however does not account for the skipper effect, which can be defined as the ability of a skipper to locate high fish densities and to harvest them. Some approaches have been developed to incorporate fishing tactics and strategies in the definition of fishing effort (Hilborn 1985; Abrahams and Healey 1990; Rijnsdorp et al. 1998).

The scope of this paper is to quantify, for a wide selection of European fleets, fisheries and stocks, the fishing tactics and strategies (skipper effect), and to evaluate the benefits of adjusting fishing effort using the skipper effect. First, a comprehensive suite of indices of fishing tactics and strategies is calculated for each vessel of the fleets under investigation. These indices reflect different characteristics of the fishermen's fishing behaviour, which may be traditional (vs. exploratory), stationary (vs. mobile), or random (vs. aggregative). The correlations between these indices will be examined. Second, the vessels' catch rates are modelled using Generalised Linear Models, using métiers (hereby defined as a set of vessel voyages targeting the same species, in the same area, and with similar gears) and the indices of fishing tactics/strategies as explanatory variables. This method is applied to identify the indices that best contribute to the variations of catch rates. In addition, nominal fishing effort is translated into effective fishing effort using the most important elements of fishing tactics/strategies identified above. Third, the 
benefits of modeling catch rates and of adjusting fishing effort are evaluated by contrasting fishing effort with available estimates of fishing mortality.

The methods developed in the different parts of the study are applied to EU fleets of different nationalities: Denmark, France, The Netherlands, The Basque Country (Spain), England (United Kingdom), harvesting different species (anglerfish (Lophius spp.), gadoids, hake (Merluccius merluccius), flatfish, deep-water species) in different fishing areas (Bay of Biscay, Celtic Sea, Western Scotland, North Sea).

\section{Material and methods}

\section{Data}

The different fishing areas, as encoded by the ICES (International Council for the Exploration of the Sea), are shown (Figure 1). The catch and effort data used for this analysis

have been derived from national fisheries databases. Data are disaggregated by vessel, fishing trip, statistical rectangle (surface: $1^{\circ}$ longitude x $0.5^{\circ}$ latitude, or approximately: 30 nautical miles x 30 nautical miles) and gear used. The recorded vessels characteristics are length, tonnage and horsepower. The type of gear (otter-trawl, pair trawls, beam-trawl, gill net, etc.) and, for most fleets, the mesh size used, were also made available.

Fishing effort units differed across countries: days fishing (Danish, Dutch and English fleets), hours fishing (Basque and French fleets). The way fishing effort was allocated among statistical rectangles during the same fishing trip also differed between countries. The proportion of fishing effort allocated in each rectangle was directly available from log-books for the French and Basque fleets, but not for the other fleets, where it had to be estimated. In the Danish and English databases, the same proportion of fishing effort was allocated to all the rectangles visited during the same fishing trip. In the Dutch database, the spatial allocation of fishing effort was calculated in proportion to the landings value achieved in each 
rectangle. In order to reduce the effect of outliers, only the fishing trips where the landings of the species being analyzed were higher than $5 \mathrm{~kg}$ were selected.

Vessels were grouped into fishing fleets, while fishing trips were grouped into métiers. Fleets and métiers have here been defined consistent with recommendations from ICES (2003a). A “fleet” was defined as a group of vessels sharing similar characteristics in terms of technical features and/or major activity. A “métier” was defined as a group of vessel voyages targeting the same (assemblage of) species and/or stocks, using similar gear, during the same period of the year and within the same area. Fleets and métiers definitions were made available by each participating country prior to the current investigation. The methods used to define these fleets and métiers differed from one country to another. For example, some countries included landing harbor to characterize fleets, and others did not. Some countries used catch profiles to identify métiers (e.g. Danish "Cod" gill-netters fishing in the North Sea), while others used a combination of inputs (e.g. Dutch beam-trawlers fishing in the North Sea with a mesh size included in the range 80-99 mm). In total, 17 fleets and 54 métiers were identified and investigated. The characteristics of the different fleets and métiers considered in this paper are summarized (Tables 1 and 2).

Total international landings and estimated fishing mortality by stock were derived from the ICES advice (ICES 2003b). Separate F estimates were given for the two anglerfish species (Lophius budegassa and Lophius piscatorius). An overall anglerfish fishing mortality was calculated by averaging the landings-weighted $\mathrm{F}$ of each of these two species. No F estimate were available for roundnose grenadier (Coryphaenoides rupestris), black scabbard (Aphanopus carbo) and blue ling (Molva dypterigia). The information for the most important stocks harvested by the fleets being investigated is summarized for 2002 (Table 3).

\section{Fishing tactics and strategies}

\section{Definitions}


We define here fishing tactics as the sequence of decisions taken at sea by a skipper at the scale of the fishing trip, and fishing strategies as the sequence of decisions taken at sea by a skipper at the scale of a year (that is the sum of the fishing tactics over the year). The sequence of decisions may include spatial effort allocation, gear, mesh size and/or métier choice. These definitions are consistent with those proposed by Laloë and Samba (1991) and Laurec et al. (1991).

Fishing tactics may be characterized through two types of variables: the métier chosen by the skipper during one fishing trip and indices that characterize the general behavior of the skipper at the scale of the fishing trip (traditional vs. exploratory, stationary vs. mobile, or random vs. aggregative).

Fishing strategies may be characterized through indices that quantify the general behavior of the skipper at the scale of the year (traditional vs. exploratory, stationary vs. mobile, or random vs. aggregative).

The skipper's general behavior is characterized by, (i) métiers choices and , (ii) indices of fishing tactics and strategies, which are described below. In most cases (unless stated explicitly), these indices may be calculated for each vessel, by fishing trip (index of fishing tactics), and by year (index of fishing strategies).

Trip- and annual-based indices of spatial diversity

These indices describe how stationary or, to the contrary, how mobile skippers have been with regards to the number of fishing grounds visited during a fishing trip or a year. Abrahams and Healey (1990) used the Shannon-Wiener diversity index, which is derived from information theory. For each vessel $v$ deploying nominal fishing effort $E n$ in each ICES rectangle $a \in A$ during fishing trip $i$, the index of fishing tactics $F T \_S W$ may be calculated as:

(1) $\quad F T_{-} S W_{v, i}=-\sum_{a \in A}\left(\frac{E n_{v, i, a}}{E n_{v, i, A}}\right) \ln \left(\frac{E n_{v, i, a}}{E n_{v, i, A}}\right)$ 
For each vessel $v$ deploying nominal fishing effort $E n$ in each ICES rectangle $a \in A$ during year $y$, the index of fishing strategy $Y E \_S W$ may be calculated as:

(2) YE_SW $W_{v, y}=-\sum_{a \in A}\left(\frac{E n_{v, y, a}}{E n_{v, y, A}}\right) \ln \left(\frac{E n_{v, y, a}}{E n_{v, y, A}}\right)$

The minimal value $F T \_S W=0$ (respectively $Y E \_S W=0$ ) occurs if only one fishing area is visited by a vessel during the same fishing trip (respectively year). The indices increase as vessels distribute their fishing effort equally between a large number of fishing areas.

If fishing effort is distributed evenly across rectangles within a trip (respectively within a year), then:

$F T \_S W=\ln (A) \quad$ (respectively $Y E \_S W=\ln (A)$ )

If fishing effort is distributed unevenly across rectangles within a trip (respectively within a year), then:

$\ln (A-1)<F T \_S W<\ln (A) \quad$ (respectively $\ln (A-1)<Y E \_S W<\ln (A)$ )

Annual index of “métier” diversity

This index describes how stationary or, to the contrary, how mobile skippers have been with regards to the number of métiers selected during a year. This index, which has been used by Ulrich and Andersen (2004), may be defined similarly to the Shannon-Wiener index of spatial diversity (2). For each vessel $v$ deploying nominal fishing effort En within each métier $m \in M$ during year $y$, the index of fishing strategy YE_SW_METIER may be calculated as: 
(3) YE_SW_METIER $R_{v, y}=-\sum_{m=1}^{M}\left(\frac{E n_{v, y, m}}{E n_{v, y, M}}\right) \ln \left(\frac{E n_{v, y, m}}{E n_{v, y, M}}\right)$

The minimal value YE_SW_METIER $=0$ occurs if only one métier is carried out by a vessel during the same year. The index increases as vessels distribute their fishing effort equally between a large number of métiers. Note that the equivalent index of fishing tactics (FT_SW_METIER) is not calculated, as only one métier is associated to each fishing trip.

If fishing effort is distributed evenly across métiers within a year, then:

$Y E \_S W \_M E T I E R=\ln (M)$

If fishing effort is distributed unevenly across métiers within a year, then:

$\ln (M-1)<Y E \_S W<\ln (M)$

Trip- and annual-based indices of spatial extent

These indices describe how stationary or, to the contrary, how mobile skippers have been with regards to the distance covered during a fishing trip or a year. These indices, based on and adapted from Salthaug and AAnes (2003), are calculated for each vessel as the effortsweighted average of all distances between fishing areas visited within one fishing trip (tactics index FT_DIST) or one year (strategy index YE_DIST):

(4) FT_DIST $T_{v, i}=\sum_{a, a^{\prime}}\left(\frac{E n_{v, i, a} \cdot E n_{v, i, a^{\prime}}}{\sum_{a, a^{\prime}}\left(E n_{v, i, a} \cdot E n_{v, i, a^{\prime}}\right.}\right) d_{v, i, a, a^{\prime}}$

(5) YE_DIST $T_{v, y}=\sum_{a, a^{\prime}}\left(\frac{E n_{v, y, a} \cdot E n_{v, y, a^{\prime}}}{\sum_{a, a^{\prime}}\left(E n_{v, y, a} \cdot E n_{v, y, a^{\prime}}\right.}\right) d_{v, y, a, a^{\prime}}$ 
where $d_{v, i, a, a^{\prime}}\left(\right.$ respectively $d_{v, y, a, a^{\prime}}$ ) is the Euclidian distance between fishing areas $a$ and $a$, for vessel $v$ and fishing trip $i$ (respectively year $y$ ). Low values of FT_DIST (respectively $Y E \_D I S T$ ) indicate that vessels have a low degree of spatial extent during one fishing trip (respectively one year).

If, during a fishing trip (respectively a year), fishing effort is evenly distributed across rectangles, we then have:

$F T_{-} D I S T_{v, i}=\frac{2}{\mathrm{~A}(\mathrm{~A}-2)} \sum_{a, a^{\prime}} d_{v, i, a, a^{\prime}}$

$Y E_{-} D I S T_{v, y}=\frac{2}{\mathrm{~A}(\mathrm{~A}-2)} \sum_{a, a^{\prime}} d_{v, y, a, a^{\prime}}$

\section{Trip- and annual-based indices of spatial patchiness}

These indices describe the patchiness of the spatial distribution of fishing effort, during a fishing trip or a year. Common indices of spatial patchiness that have been used in the fisheries literature are the simple coefficient of dispersion (Rijnsdorp et al. 1998) and the Clark-Evans index (Clark and Evans 1954; Salthaug and AAnes 2003). The index of spatial patchiness used here is the coefficient of dispersion, which measures the degree of dispersion of fishing effort within a trip (FT_PATCH) or within a year (YE_PATCH).

(6) $\quad F T_{-} P A T C H_{v, i}=\frac{s_{v, i}^{2}}{\mu_{v, i}}$

(7) YE_PATCH ${ }_{v, y}=\frac{s_{v, y}^{2}}{\mu_{v, y}}$

where $s_{v, i}^{2}$ and $\mu_{v, i}$ (respectively $s_{v, y}^{2}$ and $\mu_{v, y}$ ) are the variance and mean of fishing effort calculated over all the statistical rectangles visited by vessel v during trip i (respectively year 
y). Values of FT_PATCH and YE_PATCH larger than 1 indicate an increasingly patchy distribution, whereas values lower than 1 reflect increasingly uniform distributions. Values of 0 reflect a fully uniform distribution. Values of 1 indicate that the distribution is random.

\section{Annual index of intra-annual consistency}

This index which, to our best knowledge, is not referred to in the fisheries literature, describes how traditional or, to the contrary, how exploratory skippers have been during a fishing trip or a year. It has been included here to characterize the ability of a skipper to change its fishing pattern from one fishing trip to another. It is calculated as the difference between each fishing pattern of each fishing trip and the average fishing pattern observed over the year, scaled by the number of trips and the number of rectangles visited. This index reflects a fishing strategy, but it cannot be adapted to characterize fishing tactics.

(8) YE_IAC $C_{v, y}=\frac{1}{A . I} \sum_{i=1}^{\mathrm{I}} \sum_{a=1}^{A}\left(\frac{E n_{v, i, a}}{E n_{v, i, A}}-\frac{E n_{v, y, a}}{E n_{v, y, A}}\right)^{2}$

Low values of $Y E \_I A C$ indicate that vessels keep a similar fishing pattern from one trip to another. High values of $Y E \_I A C$ indicate that vessels have an exploratory or opportunistic behavior.

\section{Modeling catch rates}

Catch rates (CPUE, catch per unit effort) calculated for each vessel and fishing trip, are modeled using Generalized Linear Models (Mc Cullagh and Nelder 1989). The distribution of CPUE is first examined to identify and eliminate outliers. Then, in order to model catch rates, it is necessary to select a probabilistic distribution. CPUE are typically positive, skewed, continuous variables, which could typically be modeled using any of the gamma, inverse Gaussian, or log-normal distributions (Mc Cullagh and Nelder 1989). However, in order to obtain additive effects, we consider only the gamma and the log-normal 
distributions. It is possible to obtain additive effects with the gamma distribution by choosing a logarithmic link function. If CPUE are log-normally distributed, it is possible to obtain additive effects by log-transforming CPUE (Log CPUE will be normally distributed) and simply choose the identity link function. In order to choose between these 2 stochastic models, the distribution of CPUE is tested visually against a gamma distribution, using QQplots, and the distribution of $\log (\mathrm{CPUE})$ is similarly tested against a normal distribution. The most appropriate combination of explained variable and probability distribution (CPUE/gamma distribution, model type 1, or log-transformed CPUE/normal distribution, model type 2) is selected. The link function is either Logarithm (model type 1) or Identity (model type 2).

The explanatory variables are year, métier (class variables) and the different indices of fishing tactics/strategies defined above (continuous variables). The "Year" effect may quantify a combination of annual abundance changes and technical creeping. Each observation cell is a combination of vessel and fishing trip. One complete analysis is carried out for each fleet and each species examined. A general formulation of the model is:

(9a) $\quad$ Model 1: $\quad \ln (\overline{C P U E})=\hat{\alpha}+\hat{\beta}_{y}+\hat{\gamma}_{m}+\sum_{k=1}^{N I} \hat{\theta}_{k} I N D E X_{k}$

(9b) $\quad$ Model 2: $\quad \overline{\ln (C P U E)}=\hat{\alpha}+\hat{\beta}_{y}+\hat{\gamma}_{m}+\sum_{k=1}^{N I} \hat{\theta}_{k} I N D E X_{k}$

where $\alpha$ is the intercept, $\beta$ is the year effect, $\gamma$ is the métier effect, $\theta_{\mathrm{k}}$ is the regression

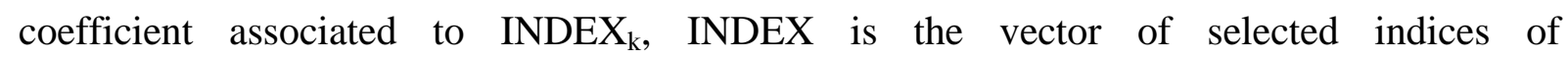
tactics/strategies.

The antilogarithmic transformation of model 1 is straightforward (10a): 
(10a) Model 1: $\quad \overline{C P U E}=\exp \left\{\hat{\alpha}+\hat{\beta}_{y}+\hat{\gamma}_{m}+\sum_{k=1}^{N I} \hat{\theta}_{k} I N D E X_{k}\right\}$

The antilogarithmic transformation of model 2 requires to correct for bias using the factor $\exp \left(\sigma^{2} / 2\right)$, where $\sigma$ is the standard error of the estimate of $\log (\mathrm{CPUE})(10 \mathrm{~b})$ :

(10b) Model 2: $\quad \overline{C P U E}=\exp \left\{\hat{\alpha}+\hat{\beta}_{y}+\hat{\gamma}_{m}+\sum_{k=1}^{N I} \hat{\theta}_{k} I N D E X_{k}-\sigma^{2} / 2\right\}$

Nevertheless, if the fit of model 2 is reasonable, then $\sigma^{2}$ is small, so the bias induced by the antilogarithmic transformation can be ignored. The estimate of CPUE under model 2 may then be simply expressed by (10a).

The model is preliminarily parameterized using the outcomes of the data exploration, which allows to select the final observation set (elimination of outliers), to select a preliminary set of candidate explanatory variables and to choose the a priori most appropriate model type (1 or 2$)$. The model chosen is validated with regards to residual plots resulting from the analysis. Residuals are plotted against predicted values and are tested visually for normal distribution (QQ-plot). Once an appropriate model type (1 or 2) is selected, the goodness of fit of the model is evaluated using the model's scaled deviance and Pearson Chisquare and also two criteria, the Akaike Information Criterion (AIC) and the Schwarz Bayesian Information Criterion (BIC). If the model chosen fits reasonably well the data, both AIC and BIC should be as low as possible. In addition, both scaled deviance and Pearson chisquare should have a chi-square distribution, with degrees of freedom equal to the number of observations minus the number of parameters estimated. It follows that the ratio between scaled deviance and degrees of freedom, and also the ratio between Pearson chi-square and degrees of freedom should be close to 1 . Finally, only the most contributive explanatory variables are retained in the final model (Type III analysis). 


\section{Adjusting fishing effort}

The method is adapted from the traditional approach (Gulland 1964 ; Robson 1966; Kimura 1981). The adjustment factors are the métier effect and the coefficients associated to the indices of fishing tactics/strategies, as estimated by (9) and (10), when the goodness of fit of the model is reasonable and when $\sigma^{2}$ may be subsequently neglected. If $\gamma_{*}$ is the effect of the reference métier, the relationship between the adjusted (or effective) log fishing effort ln_Ee and the nominal (or untransformed) log fishing effort ln_En may be expressed as

(11a) ln_Ee $e_{v, i}=\ln \_E n_{v, i}+\left(\hat{\gamma}_{m}-\hat{\gamma}_{*}\right)+\sum_{k=1}^{N I} \hat{\theta}_{k} \operatorname{INDEX} X_{k, v, i}$

Similarly, the relationship between the adjusted (or effective) fishing effort Ee and the nominal (or untransformed) fishing effort ln_En may be expressed as

$$
E e_{v, i}=E n_{v, i} \exp \left\{\left(\hat{\gamma}_{m}-\hat{\gamma}_{*}\right)+\sum_{k=1}^{N I} \hat{\theta}_{k} \operatorname{INDEX_{k,v,i}\} }\right.
$$

\section{Evaluating the benefits of adjusting fishing effort}

The benefits of adjusting fishing effort are evaluated by scrutinizing the relationship between fishing mortality and fishing effort, where effort is defined either as nominal or adjusted effort. Partial fishing mortality was calculated, for each combination of fishing vessel and fishing trip, by weighting the total F using the ratio of the vessel's and trip's landings to the total international landings for the stock under consideration. The relationship between $\mathrm{F}$ and effort was examined for the main stocks harvested by the fleets under investigation, and for which a stock assessment was available. If q represents the catchability coefficient, the relationship between partial fishing mortality F and effort E may be expressed as 
$F_{v, i}=q E_{v, i}$

The scope of this analysis is to compare the goodness of fit of the relationship between $\mathrm{F}$ and nominal effort (12a)

(12a) $\quad F_{v, i}=q E n_{v, i}$

with the goodness of fit of the relationship between $\mathrm{F}$ and adjusted effort (12b)

$$
F_{v, i}=q E n_{v, i} \exp \left\{\left(\hat{\gamma}_{m}-\hat{\gamma}_{*}\right)+\sum_{k=1}^{N I} \hat{\theta}_{k} I N D E X_{k, v, i}\right\}
$$

The comparison between (12a) and (12b) will be carried out in two ways. First, a simple no-intercept linear regression between $\mathrm{F}$ and effort will be tested with effort defined as nominal or adjusted. Second, a linear regression between log-transformed F and effort will be tested with effort defined as nominal or adjusted. For both approaches, the goodness of fit of the regressions will be appraised by, (i) eye-balling the plots between $\mathrm{F}$ and effort (or $\log (\mathrm{F})$ and $\log ($ effort)) and, (ii) comparing the values of R-square. In addition, for the second approach, a t-test has been applied to test the value of the regression slope, which should be close to 1 if the regression model (12b) is appropriate.

The methods developed in this study were implemented using SAS/STAT (1999). In particular, procedure GENMOD was used to implement the Generalized Linear Models.

\section{Results}

\section{Fishing tactics}

The indices of fishing tactics FT_SW, FT_DIST and FT_PATCH appeared to vary substantially from one fishing vessel/trip to another (Figure 2). The maximum number of rectangles visited during a trip was on average two $\left(\mathrm{FT} \_\mathrm{SW}<\ln (2)\right)$ for the Danish, English 
and Dutch fleets, three for the Basque fleets $(\ln (2)<$ FT_SW $<\ln (3))$, and five for the French fleets $(\ln (4)<$ FT_SW $<\ln (5))$. FT_SW and FT_DIST generally appeared to increase with vessel length and horsepower within the same stratum country*harbor*main gear (e.g., Danish gill-netters, Danish seiners, Danish otter-trawlers, Dutch beam-trawlers) (Figure 2). The low value of FT_PATCH for the Danish, English and Dutch fleets resulted from few rectangles $(<2)$ visited, and not from the spatial distribution of fishing effort being scattered. FT_PATCH could therefore not be used to reflect appropriately the patchiness of effort distribution, and it was not retained as an explanatory variable in subsequent analyses relative to these fleets. Given the number of rectangles visited for the French and Basque fleets was on average higher than three, the value of FT_PATCH could be interpreted to characterize the spatial distribution of fishing effort. FT_PATCH was much higher than one for these fleets, suggesting a patchy distribution of fishing effort during fishing trips. The weighted distance between rectangles visited during a fishing trip (FT_DIST) is strongly correlated to FT_SW, while FT_PATCH was generally negatively correlated with FT_SW (Figure 3).

\section{Fishing strategies}

The number of ICES rectangles visited during a year (reflected by YE_SW) is much higher than that visited during one fishing trip (reflected by FT_SW) for all fleets (Figure 2). This observation indicates shifts in fishing tactics from one fishing trip to another. The weighted distance between rectangles visited during a year (YE_DIST) is strongly correlated to YE_SW (Figure 3). YE_PATCH was generally much higher than one, indicating patchy distributions, and was negatively correlated with YE_SW. A maximum of two métiers was carried out on average by each vessel of most fleets during one year (YE_SW_METIER < $\ln (2))$. The vessels of fleets FL09 and FL12 however could on average carry out a maximum of three métiers throughout the year. Métiers shifts (as reflected by YE_METIER) were not consistently correlated with the other indices. Intra-annual shifts in fishing tactics, as 
reflected by YE_IAC, were not consistently correlated with YE_SW. The inter-annual variations in the different indices of fishing tactics and strategies were generally negligible, and these have not been represented here.

\section{CPUE analysis outputs}

The statistics resulting from the application of Generalized Linear Models to the different combination of fleets and species are summarized (Table 4). Results are only presented for the 43 combinations of fleets and species, where an appropriate model could be fitted.

The métier effect (Figures 4, 5 and 6) was significant ( $<$ 0.0001) for all combinations of fleets and species under examination.

Consider fleets FL01-FL04 (Gill-netters). The highest catch rates of plaice (Pleuronectes platessa), sole (Solea solea) and cod (Gadus morhua) are reached with nets configured for fishing these species.

Consider fleets FL05-FL08 (Danish seiners and otter-trawlers). Plaice appears to be the main target species in the North Sea, while the main target species in other areas (Skagerrak, Western Baltic Sea) is cod.

Consider fleet FL09 (English otter-trawlers). Cod and haddock (Melanogrammus aeglefinus) fishing activities can hardly be distinguished using the current definition of métiers.

Consider fleets FL10, FL13, FL14 (Beam-trawlers). With respect to sole fishing, the highest catch rates are achieved with a mesh size of $80 \mathrm{~mm}$. With respect to plaice fishing, the highest catch rates are reached when the mesh size range is of 100-134 mm for the Dutch large beam-trawlers (FL14). The relationship between mesh size and plaice CPUE is more complex for the small Dutch beam-trawlers (FL13). 
Consider fleets FL11-FL12 (French large otter-trawlers). The highest CPUE of cod and whiting (Merlangius merlangus) are achieved in the Celtic Sea, with a mesh size of 100 mm. Cod and whiting fishing activities cannot be distinguished using the current definition of métiers. With respect to saithe (Pollachius virens) fishing, the most appropriate mesh size is of $110 \mathrm{~mm}$ (FL11) and $100 \mathrm{~mm}$ (FL12), irrespective of the fishing ground visited. The relationship between CPUE and mesh size is unclear and/or area-dependent for the other species (anglerfish, blue ling, roundnose grenadier, black scabbard). Highest CPUE of blue ling, roundnose grenadier and black scabbard are associated with ICES divisions VIa (Western Scottish waters) and VII (Celtic Sea).

Consider fleets FL15-FL17 (Basque otter-trawlers). With respect to the hake (Merluccius merluccius) fishery, catch rates are the highest for pair trawlers and "Baka” otter trawlers operating in sub-area VII. With respect to anglerfish fishing, the highest catch rates are achieved in sub-area VII for fleet FL16, and in sub-area VIII for fleet FL17.

The effects of the different indices of fishing tactics and strategies on CPUE are shown (Table 4, Figures 7 and 8). The most influential indices are the Shannon-Wiener spatial diversity indices FT_SW and YE_SW and, to a lower extent, YE_DIST and YE_IAC. The effect of YE_DIST on catch rates was lower than -0.5 in 2 cases: FL08 fishing plaice and FL12 fishing whiting. The effect of YE_IAC on catch rates was higher than 0.5 for fleet FL07 fishing plaice, and lower than -0.5 for fleet FL11 fishing saithe. The other indices (FT_DIST, FT_PATCH, YE_PATCH, YE_SW_METIER) had a lesser impact on catch rates (the estimated coefficients are included in the range $[-0.5,0.5]$ ).

FT_SW is always negatively correlated with the CPUE of any combination of fleet and species. YE_SW allows to discriminate between mobile (high YE_SW) and stationary (low YE_SW) fishing strategies. The benefits of pursuing an mobile or a stationary fishing strategy are clearly case dependent. Off the 43 combinations of fleets and species 
investigated, YE_SW was positively correlated to catch rates 21 times, negatively correlated to catch rates 13 times, and not significant 9 times. The nature of the linkage between fishing strategies and catch rates generally does not appear to be clearly gear- or species-dependent. For instance, with regards to the flatfish fishery, pursuing a mobile strategy appears to be attractive (YE_SW > 0) for fleets FL01 and FL10, but not for fleet FL14. Such contrasted results are also observed for the fisheries harvesting cod, anglerfish, blue ling and black scabbard. For both fleets FL11 and FL12, vessels pursuing a more mobile strategy have the highest catch rates of roundnose grenadier. Overall, the impact on catch rates of fishing strategies (as reflected by YE_SW) appears to be of a more complex nature than that of fishing tactics (as reflected by FT_SW).

Having examined the respective effect of métiers choices and of the different indices of fishing tactics and strategies, we examined the relative contribution of each factor to catch rates variations. In most cases, the métier effect appeared to be dominant. This is illustrated in Figure 9 for selected combinations of fleets and species. In these examples, the "métier" effect clearly discriminates catch rates for fleets FL04 fishing plaice and sole, FL09 fishing cod, FL10 fishing sole, FL11 fishing saithe and FL15 fishing hake. For these combinations, catch rates are reasonably correlated with the other components of fishing power (indices of fishing tactics and strategies) within each important métier stratum.

\section{Relation between fishing effort and fishing mortality}

The relationship between fishing effort and fishing mortality and also the relationship between $\log ($ effort $)$ and $\log (\mathrm{F})$ were investigated in situations where a stock assessment was available, i.e. 38 combinations of fleets and stocks. Adjusting fishing effort led to a substantial increase in the R-square of the regression between fishing mortality and effort, except for fleets FL08 harvesting North Sea plaice, FL09 harvesting North Sea cod and FL17 harvesting Celtic Sea/Bay of Biscay anglerfish (Table 5). In all but one case (FL05 fishing 
North Sea cod), adjusting fishing effort led to a substantial improvement of the relationship between $\log (\mathrm{F})$ and $\log ($ effort) (Table 6, Figures 10 and 11). The average slope of the regression with adjusted effort was in the range [0.95-1.05] for 15 of the combinations of fleets and stocks, and it was not significantly different from 1 for 11 of these combinations. For these 11 combinations, the traditional assumption that fishing mortality is directly proportional to adjusted fishing effort is reasonable, provided effort has been adjusted using the skipper effect. For the other combinations, adjusting fishing effort generally leads to a substantial improvement of the relationship between $\mathrm{F}$ and effort. However, $\mathrm{F}$ is not directly proportional to the adjusted fishing effort.

\section{Discussion}

The three objectives of this study were, (i) to characterize and quantify, using a set of descriptive variables, shifts in fishing tactics and strategies for a wide spectrum of European fleets, (ii) to evaluate the extent to which these variables may be used to model catch rates and, (iii) to assess the benefits of adjusting fishing effort with the coefficients derived from the analysis (ii).

The fishing tactics index FT_SW describes the fishermen's mobility at the scale of a fishing trip, while the fishing strategy YE_SW features the same aspects, at the scale of the year. FT_SW and YE_SW increased with vessel length and horsepower, which could be anticipated, since larger vessels have in principle the potential for exploring more rectangles. Catch rates were strongly correlated to métiers choices and to the indices FT_SW and YE_SW. In particular, FT_SW was negatively correlated to the catch rates of each combination of fleets and species investigated. This result was expected, for two main reasons. First, because fishing vessels search for fish aggregations, their catchability is anticipated to increase when the area occupied by the stock decreases. Given that the spatial distribution of the fleet gives an indication of the area occupied by the targeted population, 
vessels of limited spatial distribution within a trip have the highest catchability. Second, FT_SW quantifies to some extent the ability of skippers to locate high fish densities during a fishing trip. One may anticipate that during a fishing trip, vessels with high FT_SW have been searching fish aggregations for a long time, while vessels with low FT_SW have been more efficient in finding and subsequently harvesting these aggregations. These results bear out the findings of Salthaug and AAnes (2003), who investigated the linkage between catch rates and the distribution of the fishing effort deployed by the Norwegian fleets harvesting gadoids in the North Sea and the Barents Sea. FT_SW appears to be a reasonable candidate to quantify the skipper's effect during a fishing trip.

The influence of fishing strategies on catch rates was of a more complex nature. Depending on the combination of fleet and species, YE_SW was positively or negatively correlated to the catch rates. One may anticipate that there was little benefit visiting many fishing grounds for the vessels and fisheries where negative correlation was found. The vessels pursuing such a stationary strategy are referred to by Hilborn (1985) as "areaspecialists”. These vessels specialize in a particular area and learn everything possible about catching fish in that area. For other vessels and fisheries, a broad distribution of fishing effort proved to be an appropriate strategy to promote high yields. These results bear out those of Abrahams and Healey (1990), who found that mobile vessels had the highest catch rates of sockeye salmon. Such vessels, which are referred to by Hilborn (1985) as "movementspecialists”, are reputed to develop skills appropriate to any area and then to fish opportunistically in a large number of different areas in order to maximize catch rates. In addition, stationary strategies could lead to local depletion for non-resilient species, and thereby adversely impact catch rates (Rijnsdorp et al. 2000a). Both interpretations may explain why French vessels pursuing a mobile strategy have the highest catch rates of roundnose grenadier, which is a non-resilient species, and the commercial exploitation of 
which has developed only since the early nineties, so new aggregations are still being discovered. YE_SW may be an appropriate indicator to distinguish between area- and movement-specialists. However, it was not possible in this study to determine the factors that made an exploratory strategy more or less attractive than a stationary strategy. Such an investigation would require getting more insights in the factors that condition the fishers' decision-making process, e.g. spatial and time distribution of the harvested species, market shifts, management regulations.

Consider the other indices of fishing tactics and strategies (FT_DIST, FT_PATCH, YE_DIST, YE_PATCH, YE_IAC, YE_SW_METIER). The positive correlation between FT_DIST and FT_SW (respectively between YE_DIST and YE_SW) was expected, since the distance covered by a vessel during a fishing trip (respectively a year) is likely to increase with the number of rectangles visited. The negative correlation between FT_PATCH and FT_SW (respectively YE_PATCH and YE_SW) could be explained by the fact that vessels fishing on aggregations are expected to visit less spatial units than vessels having a more scattered distribution. Overall, the impact of the other indices of fishing tactics and strategies on catch rates was limited. Regarding FT_DIST, FT_PATCH, YE_DIST and YE_PATCH, a possible explanation is that the validity of these indices is highly dependent on the spatial resolution used to define the basic observation cells. In this study, the basic spatial unit was the ICES statistical rectangle $\left(1^{\circ}\right.$ longitude x $0.5^{\circ}$ latitude). One ICES rectangle may host different species aggregations, especially when those are located at distinct depth strata (e.g., saithe and roundnose grenadier off Western Scotland). Given fishing vessels search these aggregations, FT_DIST, FT_PATCH, YE_DIST and YE_PATCH should really be calculated at a much finer spatial scale. Ideally, these indices should be derived based on haul-by-haul data, and the geographical position of fishing vessels should be accurately documented. Such data are currently being collected and analyzed by the participants of this exercise, and results 
of the analyses should be released in the short future. When such data become available, indices such as FT_DIST, FT_PATCH, YE_DIST, YE_PATCH, but also alternative measures of the fishing effort dispersion (e.g. coefficient of variation, Clark and Evans coefficient of dispersion) could be examined in relation to catch rates variations.

The linkage between catch rates and métier choices generally highlights contrasts in fish availability and management regimes in the different areas fished, which may be illustrated by several examples. First, the North Sea cod stock has recently reached historical minima, and fishermen targeting this stock have to abide by restrictive management measures (e.g. low catch quotas, fishing effort limits). Management of cod fishing is also restrictive in the Baltic Sea, but cod is by far the main demersal stock which is economically exploitable by fishers in that area. As a result, plaice appears to be the main target species of fleets FL05FL08 (Danish seiners and otter-trawlers) in the North Sea, while the main target species in the Western Baltic Sea is cod. Second, for the Dutch and English beam trawlers harvesting sole and plaice, the most appropriate mesh size for plaice and sole fishing is directly linked with the different combinations of mesh size regulations and by-catch limits applicable in the North Sea. Third, with respect to saithe fishing, the mesh size associated to the highest catch rates is of $110 \mathrm{~mm}$ for FL11, and $100 \mathrm{~mm}$ for FL12. This difference in mesh size likely results from the inconsistency in the mesh size regulations in force in the main areas visited by the vessels targeting saithe. Vessels belonging to FL11 target saithe mainly in the North Sea, where the minimal mesh size is of $110 \mathrm{~mm}$ since 2001. Vessels from FL12 target saithe mainly off Western Scotland, where they have to abide by a minimal mesh size of $100 \mathrm{~mm}$.

The fishing effort of the fleets under investigation was adjusted, based on the analysis of the variations in catch rates in relation to both the fishing métiers and the indices of fishing tactics and strategies. The link between fishing mortality and effort was then investigated for the 38 combinations of fleets and stocks. In most of the cases, adjusting fishing effort led to a 
substantial gain in the precision of the relationship between fishing mortality and fishing effort. In particular, for 11 out of the 38 combinations of fleets and stocks, fishing mortality was reasonably correlated and directly proportional to fishing effort. This result has implication for stock assessments and fisheries management. In terms of stock assessment, those fleets could be appropriate tuning fleets to assess the stocks under consideration. In terms of management, a unit reduction of those fleets' adjusted effort would lead to a unit reduction of the stocks they harvest.

Nevertheless, for 27 out of the 38 combinations, fishing mortality was poorly correlated and/or not directly proportional to adjusted fishing effort. This indicates that this study goes one step towards the right direction, but also that more research is needed to carry on the development of a reliable fishing effort model.

First, this study investigated the impact of tactical and strategic adaptations on catchability. Other aspects including the technological development of fishing vessels, gears and equipment on-board, as well as time and spatial changes in fish availability have not been investigated here. The influence of these factors on catchability has been evidenced in the past, and sometimes used to adjust fishing effort (Kimura 1981; Fernö and Olsen 1994; Salthaug 2001). When the relevant data become available, there is scope developing an effort model that would combine both tactical changes and technological development.

Second, the results of this study are dependent on the quality of the catch and effort data derived from log-books. In particular, misreporting and discarding are believed to occur in European fisheries, and such practices are likely to adversely alter data quality. Nevertheless, the datasets used for this exercise are also exploited to run routine ICES stock assessments under the auspices of the ICES, and they are currently believed to be the best source of data available to carry out fisheries analyses. An improvement would be to apply 
the methodology presented here to a dataset where catch and effort data are accurately recorded on a haul-by-haul basis.

Third, catch rates were in this study analyzed for each fishing vessel independently, thereby ignoring the influence of vessels interactions (collaboration or competition) on catch rates. These aspects have been investigated by Gillis et al. (1993), Gillis and Peterman (1998), and Rijnsdorp et al. (2000b). For instance, Rijnsdorp et al. (2000b) showed that the Dutch beam trawlers harvesting flatfish, a possible $10 \%$ increase in vessels revenue may be brought about when vessel density is reduced by $25 \%$.

Fourth, improving the relationship between fishing effort and fishing mortality requires not only to seek the most appropriate adjustment of fishing effort, but also to enhance the estimate of fishing mortality. In this study, fishing mortality was derived from ICES stock assessments, and then partitioned into vessels and trips according to their relative catches. This simple approach however generates a number of concerns. The most obvious problem in that the relationship between $\mathrm{F}$ and effort may not be evaluated when no reliable stock assessments outputs are available (e.g. blue ling, roundnose grenadier, black scabbard). Besides, when they exist, $\mathrm{F}$ estimates from stock assessments are uncertain, and more particularly in the most recent years of the assessment, corresponding to the non-converged part of the VPA. Finally, the fleets used in this study are sometimes also used as tuning fleets to calibrate the VPA (e.g., French trawlers for the North Sea saithe assessment), which may generate an undesirable case for circularity.

Finally, other methods than GLM could be contemplated to model catch rates. In particular, the delta-GLM could be helpful to model the catch rates characterized by a large proportion zero observations and highly skewed positive values (Dick 2004).

Further investigations could then be carried out to investigate the determinism of the shifts in fishing tactics and strategies. Fishermen's behavior highly depends on socio- 
economics, management regulations and stock abundance (Holley and Marchal, 2004). Modeling the linkage between shifts in management regimes and fishermen's behavior would complement approaches aiming at improving the relationship between fishing mortality and

fishing effort. The successful coupling of both compartments could benefit directly to fisheries managers, who would be in a better position to forecast the responses of both fleets and fish stocks, to shifts in management regimes.

\section{Acknowledgements}

This work was funded through the TECTAC project (Technological and Tactical adaptations of important EU fleets) by the European Union (DG Fisheries, study no. QLRT-2001-01291) and by the Basque Country Government (Industry, Agriculture and Fisheries Department). This support is gratefully acknowledged. We are also indebted to ICES for providing stock assessment outputs. 


\section{References}

Abrahams, M.V., and Healey, M.C. 1990. Variation in the competitive abilities of fishermen and its influence on the spatial distribution of the British Columbia Salmon Troll Fleet. Can. J. Fish. Aquat. Sci. 47: 1116-1121.

Arreguin-Sanchez, F. 1996. Catchability : a key parameter for fish stock assessment. Rev. Fish Biol. Fish. 6: 221-242.

Clark, P.J., and Evans, F.C. 1954. Distance to the nearest neighbor as a measure of spatial relationships in populations. Ecology 35: 445-453.

Cook, R.M., and Armstrong, D.M. 1985. Changes in the catchability of cod, haddock, and whiting associated with the Scottish seine-net fleet. J. Cons. Intern. Explor. Mer 42: 171-178.

Dick, E.J. 2004. Beyond 'lognormal versus gamma ' : discrimination among error distributions for generalized linear models. Fish. Res. 70: 351-366.

Fernö, A., Olsen, S. 1994. Marine fish behaviour in capture and abundance estimation. Fishing News Books. Blackwell Scientific Publications, Oxford.

Gillis, D.M., Peterman, R.M., and Tyler, A.V. 1993. Movement dynamics in a fishery: application of the ideal free distribution to spatial allocation of effort. Can. J. Fish. Aquat. Sci. 50: 323-333.

Gillis, D.M., and Peterman, R.M. 1998. Implications of interference among fishing vessels and the ideal free distribution to the interpretation of CPUE. Can. J. Fish. Aquat. Sci. 55: $37-46$.

Gulland, J.A. 1964. Catch per unit effort as a measure of abundance. Rapport des ProcèsVerbaux de la Réunion du Conseil International pour l’Exploration de la Mer 155: 6670. 
Hilborn, R. 1985. Fleet dynamics and individual variation : why some people catch more fish than others. Can. J. Fish. Aquat. Sci. 42: 2-13.

Holley, J.-F., and Marchal P. 2004. Fishing strategy development under changing conditions: examples from the French offshore fleet fishing in the North Atlantic. ICES J. Mar. Sci. 61: 1410-1431.

Hovgaard, H. 1996. Effect of twine diameter on fishing power of experimental gill nets used in Greenland waters. Can. J. of Fish. Aquat. Sci., 53: 1017-1017.

ICES 2003a. Report of the Study Group on Fishery-Based Forecasts. ICES CM2003 / ACFM:08, 37 pp.

ICES 2003b. Report of the Advisory Committee on Fishery Management, October 2003. [http://www.ices.dk/committe/acfm/comwork/report/asp/acfmrep.asp].

Kimura, D.K. 1981. Standardised measures of relative abundance based on modeling $\log (\mathrm{CPUE})$ and their application toPacific ocean perch (Sebastes alutus). J. Cons. Intern. Explor. Mer 39: 211-218.

Laloë, F., and Samba 1991. A simulation model of artisanal fisheries of Senegal. ICES Mar. Sci. Symp. 193: 281-286.

Laurec, A., Biseau, A., and Charuau, A. 1991. Modeling technical interactions. ICES Mar. Sci. Symp. 193: 225-236.

Mahévas, S. , Sandon, Y., and Biseau, A. 2004. Quantification of annual variations in fishing power and explanation of differences in efficiency by technical characteristics: an application to the bottom-trawlers of South-Brittany targeting anglerfish from 1983 to 1998. ICES J. Mar. Sci. 61 : 71-83.

Marchal, P., Ulrich, C., Korsbrekke, K., Pastoors, M., and Rackham, B. 2002. A comparison of three indices of fishing power on some demersal fisheries of the North Sea. ICES J. Mar. Sci. 59: 604-623. 
Marchal, P., Ulrich, C., Korsbrekke, K., Pastoors, M., and Rackham, B. 2003. Annual trends in catchability and fish stock assessments. Sci. Mar. 67 (Suppl. 1): 63-73.

Mc Cullagh, P., and Nelder, J.A. 1989. Generalized Linear Models. Chapman \& Hall, New York.

Overholtz, W.J., Edwards, S.F., and Brodziak, K.T. 1995. Effort control in the the New England groundfish fishery: a bio-economic perspective. Can. J. Fish. Aquat. Sci. 52: 1944-1957.

Pascoe, S., Andersen, J.L., and de Wilde, J.W. 2001. The impact of management regulation on the technical efficiency of vessels in the Dutch beam trawl fishery. Eur. Rev. Agric. Econ. 28: 187-206.

Rijnsdorp, A.D., Buys, A.M., Storbeck, F., and Visser, E.G. 1998. Micro-scale distribution of beam trawl effort in the southern North Sea between 1993 and 1996 in relation to the trawling frequency of the sea bed and the impact on benthic organisms. ICES J. Mar. Sci. 55: 403-419.

Rijnsdorp, A.D., van Mourik Broekman, P.L., and Visser, E.G. 2000a. Competitive interactions among beam trawlers exploiting local patches of flatfish in the North Sea. ICES J. Mar. Sci. 57: 894-902.

Rijnsdorp, A.D., Dol, W., Hoyer, M., and Pastoors, M.A. 2000b. Effects of fishing power and competitive interactions among vessels on the effort allocation on the trip level of the Dutch beam trawl fleet. ICES J. Mar. Sci. 57: 927-937.

Robson, D.S. 1966. Estimation of the relative fishing power of individual ships. ICNAF Res. Bull. 3: 5-14.

Rose, C.S., and Nunnallee, E.P. 1998. A study of changes in groundfish trawl catching efficiency due to differences in operating width, and measures to reduce width variation. Fish. Res. 36: 139-147. 
Salthaug, A. 2001. Adjustment of commercial trawling effort for Atlantic cod, Gadus morhua, due to increasing catching efficiency. Fish. Bull. 99: 338-342.

Salthaug, A., and AAnes, S. 2003. Catchability and the spatial distribution of fishing vessels. Can. J. Fish. Aquat. Sci. 60: 259-268.

Sangster, G.I., and Breen, M. 1998. Gear performance and catch comparison trials between a single trawl and a twin rigged trawl. Fish. Res. 36: 15-26.

SAS/STAT 1999. SAS Institute Inc., SAS/STAT User’s Guide, Version 8, Cary, NC, 3884 pp.

Swain, D.P., Nielsen, G., Sinclair, A.F., and Chouinard, G.A. 1994. Changes in catchability of Atlantic cod (Gadus morhua) to an otter-trawl fishery and research survey in the southern Gulf of St Lawrence. ICES J. Mar. Sci. 51 : 493-504.

Ulrich, C., and Andersen, B.S. 2004. Dynamics of fisheries, and the flexibility of vessel activity in Denmark between 1989 and 2001. ICES J. Mar. Sci. 61 : 308-322.

Ulrich, C., Pascoe, S., Sparre, P.J., de Wilde, J.-W., and Marchal, P. 2002. Influence of trends in fishing power on bio-economics in the North Sea flatfish fishery regulated by catches- or by effort quotas. Can. J. Fish. Aquat. Sci. 59: 829-843. 
Table 1. Summary of the international fleets investigated. DSN: Danish seiners; GN: gill netters; OTB: otter trawlers; TBB: beam trawlers.

\begin{tabular}{|c|c|c|c|c|c|}
\hline Country & Period & Harbour(s) & Main gear & Length (m) or power (hp) & Reference name \\
\hline \multirow[t]{8}{*}{ Denmark } & 1999-2003 & West. Jutland & GN & $0-12 \mathrm{~m}$ & FL01 \\
\hline & & & & $12-15 \mathrm{~m}$ & FL02 \\
\hline & & & & $15-18 \mathrm{~m}$ & FL03 \\
\hline & & & & $18-24 \mathrm{~m}$ & FL04 \\
\hline & & & DSN & $15-18 \mathrm{~m}$ & FL05 \\
\hline & & & & $18-24 \mathrm{~m}$ & FL06 \\
\hline & & & OTB & $15-18 \mathrm{~m}$ & FL07 \\
\hline & & & & $18-24 \mathrm{~m}$ & FL08 \\
\hline UK & $2000-2002$ & East. Coast & OTB & $10-19 \mathrm{~m}$ & FL09 \\
\hline (England) & & & TBB & $30-39 \mathrm{~m}$ & FL10 \\
\hline \multirow[t]{2}{*}{ France } & $1999-2003$ & Boulogne & OTB & $40+m$ & FL11 \\
\hline & & South. Brittany & ОТВ & $24+m$ & FL12 \\
\hline \multirow[t]{2}{*}{ Netherlands } & $1995-2002$ & All & TBB & 300-1500 hp & FL13 \\
\hline & & & & $1500+$ hp & FL14 \\
\hline \multirow{3}{*}{$\begin{array}{l}\text { Spain } \\
\text { (Basque country) }\end{array}$} & $1995-2003$ & Ondorroa & OTB & $20-29$ & FL15 \\
\hline & & & & $30-39$ & FL16 \\
\hline & & Pasaia & OTB & $30-39$ & FL17 \\
\hline
\end{tabular}


Table 2. Summary of the main métiers investigated. DSN: Danish seiners; GN: gill netters; LL: long-liners; OTB: otter trawlers; MTB: multiple bottom trawlers; PTB: pair trawlers; TBB: beam trawlers; VHVO: very high vertical opening. DK: Denmark, EN: England, FR: France, NL: The Netherlands, BC: Basque country. Target species are anglerfish (Lophius spp.), black scabbard (Aphanopus carbo), blue ling (Molva dypterigia), cod (Gadus morhua), haddock (Melanogrammus aeglefinus), hake (Merluccius merluccius), megrim (Lepidorhombus spp.), Nephrops (Nephrops norvegicus), plaice (Pleuronectes platessa), roundnose grenadier (Coryphaenoides rupestris), saithe (Pollachius virens), sole (Solea solea), turbot (Scophtalmus maximus), whiting (Merlangius merlangus).

\begin{tabular}{|c|c|c|c|c|c|}
\hline Gear & $\begin{array}{l}\text { Mesh size (mm) } \\
\text { or target species }\end{array}$ & ICES division & Fishing ground & $\begin{array}{l}\text { Reference } \\
\text { name }\end{array}$ & Target species \\
\hline \multirow[t]{5}{*}{ GN } & Cod & IVa-c & North Sea & DK_MET01 & Cod \\
\hline & Hake & & & DK_MET02 & Plaice \\
\hline & Plaice & & & DK_MET03 & Sole \\
\hline & Sole & & & DK_MET04 & \\
\hline & Turbot & & & DK_MET05 & \\
\hline LL & - & & & DK_MET06 & \\
\hline \multirow[t]{3}{*}{ DSN } & - & IIIaN & Skagerrak & DK_MET07 & \\
\hline & & IIId & W. Baltic & DK_MET08 & \\
\hline & & IVa-c & North Sea & DK_MET09 & \\
\hline MTB & $0-29$ & IVa-c & North Sea & DK_MET10 & \\
\hline \multirow[t]{6}{*}{ ОТВ } & 70-89 & IVa-c & North Sea & DK_MET11 & \\
\hline & $90-104$ & IIIaN & Skagerrak & DK_MET12 & \\
\hline & $90-104$ & IIIaS & Kattegat & DK_MET13 & \\
\hline & $90+$ & IIId & W. Baltic & DK_MET14 & \\
\hline & $90-104$ & IVa-c & North Sea & DK_MET15 & \\
\hline & $105^{+}$ & IIIaN & Skagerrak & DK_MET16 & \\
\hline
\end{tabular}




\begin{tabular}{|c|c|c|c|c|c|}
\hline & $105+$ & IIIaS & Kattegat & DK_MET17 & \\
\hline & $105+$ & IVa-c & North Sea & DK_MET18 & \\
\hline OTB & 0-79 - Mix & IVa-c & North Sea & EN_MET01 & Cod \\
\hline & 70-99 - Nephrops & IVa-c & North Sea & EN_MET02 & Haddock \\
\hline & 80+ - Haddock & & & EN_MET03 & Plaice \\
\hline & 80+ - Mix & & & EN_MET04 & Sole \\
\hline & $80+$ - Sole & & & EN_MET05 & \\
\hline & $100+-$ Cod & & & EN_MET06 & \\
\hline TBB & Mix & & & EN_MET07 & \\
\hline & 80+ - Plaice & & & EN_MET08 & \\
\hline & $80+-$ Sole & & & EN_MET09 & \\
\hline OTB & $80-99$ & VIa & W. Scotland & FR_MET01 & Black Scabbard \\
\hline & $80-99$ & VIIb-c,e-k & Celtic Sea & FR_MET02 & Blue ling \\
\hline & 80-99 & VIIIa-b & Bay of Biscay & FR_MET03 & Cod \\
\hline & $100-109$ & IVa-c & North Sea & FR_MET04 & Anglerfish \\
\hline & 100-109 & VIa & W. Scotland & FR_MET05 & Whiting \\
\hline & 100-109 & VIIb-c,e-k & Celtic Sea & FR_MET06 & Saithe \\
\hline & 100-109 & VIIIa-b & Bay of Biscay & FR_MET07 & \\
\hline & $110-129$ & IVa-c & North Sea & FR_MET08 & \\
\hline & $110-129$ & VIa & W. Scotland & FR_MET09 & \\
\hline & $110-129$ & VIIb-c,e-k & Celtic Sea & FR_MET10 & \\
\hline & $110-129$ & VIIIa-b & Bay of Biscay & FR_MET11 & \\
\hline & $130+$ & IVa-c & North Sea & FR_MET12 & \\
\hline & $130+$ & VIa & W. Scotland & FR_MET13 & \\
\hline & $130+$ & VIIb-c,e-k & Celtic Sea & FR_MET14 & \\
\hline TBB & $0-69$ & IVa-c & North Sea & NL_MET01 & Plaice \\
\hline & 70-79 & & & NL_MET02 & Sole \\
\hline & 80-99 & & & NL_MET03 & \\
\hline & $100-119$ & & & NL_MET04 & \\
\hline & $120-134$ & & & NL_MET05 & \\
\hline
\end{tabular}




\begin{tabular}{llllll}
\hline 135+ & & & NL_MET06 & \\
\hline OTB “Baka” & VIa & W. Scotland & BC_MET01 & Hake \\
& VIIb-c,e-k & Celtic Sea & BC_MET02 & Megrim \\
& VIIIa-b,d & Bay of Biscay & BC_MET03 & Anglerfish \\
& VIIb-c,e-k & Celtic Sea & BC_MET04 & \\
& "Bou” & VIIIa-b,d & Bay of Biscay & BC_MET05 & \\
& VIIb-c,e-k & Celtic Sea & BC_MET06 & \\
& VIIIa-b,d & Bay of Biscay & BC_MET07 & \\
\hline
\end{tabular}


Table 3. Total international landings $(\mathrm{t})$ and mean fishing mortality (averaged over age classes) in 2002, for the most important stocks harvested by the fleets under investigation. Species investigated are anglerfish (Lophius spp.), cod (Gadus morhua), haddock (Melanogrammus aeglefinus), hake (Merluccius merluccius), megrim (Lepidorhombus spp.), plaice (Pleuronectes platessa), saithe (Pollachius virens), sole (Solea solea), whiting (Merlangius merlangus).

\begin{tabular}{llll}
\hline Species & Stock & Landings & Mean F \\
\hline Cod & Celtic Sea cod & 9119 & 0.96 \\
& North Sea cod & 54400 & 0.61 \\
\hline Haddock & North Sea haddock & 105194 & 0.36 \\
\hline Hake & Northern hake & 40312 & 0.24 \\
\hline Megrim & Celtic Sea \& Bay of Biscay megrim & 17402 & 0.39 \\
\hline Anglerfish & Celtic Sea \& Bay of Biscay anglerfish & 6513 & 0.31 \\
& North Sea \& West Scotland anglerfish & 13110 & 0.72 \\
\hline Plaice & North Sea plaice & 70200 & 0.51 \\
\hline Sole & North Sea sole & 16945 & 0.48 \\
\hline Saithe & North Sea \& West Scotland saithe & 121833 & 0.21 \\
\hline Whiting & Celtic Sea whiting & 13083 & 0.53 \\
\hline
\end{tabular}


Table 4. Summary of the statistics assessing the Goodness of Fit of the Generalised Linear Models applied to each combination of country, fleet and species: model type (1: gamma distribution/logarithmic link function; 2: normal distribution/identity link function), degrees of freedom (DF), ratio of scaled deviance to DF (SCD/DF), ratio of scaled Pearson chi-square DF (SCC/DF). "X” indicates where an explanatory variable is significant ( $<$ 0.05). The "métier” and the “year” effects were always significant $(\mathrm{p}<0.05)$. Species investigated are anglerfish (Lophius spp.), black scabbard (Aphanopus carbo), blue ling (Molva dypterigia), cod (Gadus morhua), haddock (Melanogrammus aeglefinus), hake (Merluccius merluccius), plaice (Pleuronectes platessa), roundnose grenadier (Coryphaenoides rupestris), saithe (Pollachius virens), sole (Solea solea), whiting (Merlangius merlangus).

\begin{tabular}{|c|c|c|c|c|c|c|c|c|c|c|c|c|c|c|}
\hline \multirow[b]{2}{*}{ Country } & \multirow[b]{2}{*}{ Fleet } & \multirow[b]{2}{*}{ Species } & \multicolumn{4}{|c|}{ Model } & \multirow{2}{*}{$\begin{array}{l}\mathrm{FT}_{-} \\
\mathrm{SW}\end{array}$} & \multirow{2}{*}{$\begin{array}{l}\text { FT_ } \\
\text { DIST }\end{array}$} & \multirow{2}{*}{$\begin{array}{l}\mathbf{F T}_{-} \\
\text {PATCH }\end{array}$} & \multirow{2}{*}{$\begin{array}{l}\text { YE_ } \\
\text { DIST }\end{array}$} & \multirow{2}{*}{$\begin{array}{l}\text { YE_ }_{-} \\
\text {IAC }\end{array}$} & \multirow{2}{*}{$\begin{array}{l}\mathrm{YE}_{-} \\
\text {PATCH }\end{array}$} & \multirow{2}{*}{$\begin{array}{l}\text { YE_ } \\
\text { SW }\end{array}$} & \multirow{2}{*}{$\begin{array}{l}\text { YE_ } \\
\text { SW_METIER }\end{array}$} \\
\hline & & & type & DF & SCD/DF & SCC/DF & & & & & & & & \\
\hline \multirow[t]{9}{*}{ Denmark } & FL01 & Cod & 2 & 4011 & 1.00 & 1.00 & & & & $\mathrm{X}$ & $\mathrm{X}$ & & & \\
\hline & & Plaice & 2 & 3614 & 1.00 & 1.00 & & & & & & & $X$ & \\
\hline & & Sole & 2 & 1913 & 1.01 & 1.01 & & & & $\mathrm{X}$ & $X$ & & $\mathrm{X}$ & \\
\hline & FL02 & Cod & 2 & 5746 & 1.00 & 1.00 & & & & $\mathrm{X}$ & $\mathrm{X}$ & & & \\
\hline & & Plaice & 2 & 4958 & 1.00 & 1.00 & & & & & & & $X$ & \\
\hline & & Sole & 2 & 2428 & 1.01 & 1.01 & & & & $X$ & $X$ & & $\mathrm{X}$ & \\
\hline & FL03 & Cod & 2 & 5819 & 1.00 & 1.00 & $X$ & & & & & & & $X$ \\
\hline & & Plaice & 2 & 4321 & 1.00 & 1.00 & & & & $X$ & $X$ & $X$ & $X$ & \\
\hline & & Sole & 2 & 2619 & 1.00 & 1.00 & & & & & & & & $X$ \\
\hline
\end{tabular}




\begin{tabular}{|c|c|c|c|c|c|c|c|c|c|c|c|c|c|c|}
\hline & FL04 & Cod & 1 & 4303 & 1.10 & 0.83 & $\mathrm{X}$ & & & $\mathrm{X}$ & $\mathrm{X}$ & & $\mathrm{X}$ & \\
\hline & & Plaice & 2 & 2505 & 1.00 & 1.00 & & & & $\mathrm{X}$ & & & & \\
\hline & & Sole & 2 & 1564 & 1.01 & 1.01 & & & & & & & $\mathrm{X}$ & $\mathrm{X}$ \\
\hline & FL05 & Cod & 2 & 1108 & 1.01 & 1.01 & $\mathrm{X}$ & & & & $\mathrm{X}$ & & $\mathrm{X}$ & \\
\hline & & Plaice & 1 & 1111 & 1.17 & 0.94 & $\mathrm{X}$ & & & & $\mathrm{X}$ & & $\mathrm{X}$ & \\
\hline & FL06 & Cod & 1 & 4406 & 1.16 & 1.10 & $\mathrm{X}$ & & & & $\mathrm{X}$ & & & \\
\hline & & Plaice & 2 & 4210 & 1.00 & 1.00 & $\mathrm{X}$ & & & & & & $\mathrm{X}$ & \\
\hline & FL07 & Cod & 2 & 4260 & 1.00 & 1.00 & & & & & $\mathrm{X}$ & & & $\mathrm{X}$ \\
\hline & & Plaice & 2 & 4329 & 1.00 & 1.00 & & & & & $\mathrm{X}$ & $\mathrm{X}$ & $\mathrm{X}$ & \\
\hline & FL08 & Cod & 2 & 4886 & 1.00 & 1.00 & & & & $\mathrm{X}$ & & & $\mathrm{X}$ & \\
\hline & & Plaice & 2 & 4213 & 1.00 & 1.00 & & & & $\mathrm{X}$ & & $\mathrm{X}$ & $\mathrm{X}$ & \\
\hline England & FL09 & Cod & 2 & 45651 & 1.00 & 1.00 & & & & & & & $\mathrm{X}$ & \\
\hline & & Haddock & 2 & 31952 & 1.00 & 1.00 & & & & & $\mathrm{X}$ & & $\mathrm{X}$ & \\
\hline & FL10 & Plaice & 1 & 7268 & 1.04 & 0.97 & $\mathrm{X}$ & & & & $\mathrm{X}$ & & $\mathrm{X}$ & \\
\hline & & Sole & 2 & 4153 & 1.00 & 1.00 & $\mathrm{X}$ & & & & & & $\mathrm{X}$ & \\
\hline France & FL11 & Blue Ling & 2 & 1121 & 1.02 & 1.02 & $\mathrm{X}$ & $\mathrm{X}$ & & & & & $\mathrm{X}$ & \\
\hline & & Black Scabbard & 2 & 842 & 1.02 & 1.02 & & $\mathrm{X}$ & $\mathrm{X}$ & & & $X$ & $\mathrm{X}$ & \\
\hline & & Saithe & 2 & 1085 & 1.02 & 1.02 & $\mathrm{X}$ & & $\mathrm{X}$ & $\mathrm{X}$ & $\mathrm{X}$ & $\mathrm{X}$ & $\mathrm{X}$ & \\
\hline & & R. Grenadier & 2 & 853 & 1.03 & 1.03 & $\mathrm{X}$ & & $\mathrm{X}$ & & $\mathrm{X}$ & $\mathrm{X}$ & $\mathrm{X}$ & \\
\hline
\end{tabular}




\begin{tabular}{|c|c|c|c|c|c|c|c|c|c|c|c|c|c|c|}
\hline \multirow{7}{*}{\multicolumn{2}{|c|}{ FL12 }} & Blue Ling & 2 & 2983 & 1.01 & 1.01 & $\mathrm{X}$ & & $X$ & & & $\mathrm{X}$ & $X$ & $\mathrm{X}$ \\
\hline & & Black Scabbard & & 3151 & 1.01 & 1.01 & $\mathrm{X}$ & $\mathrm{X}$ & & & $\mathrm{X}$ & & $\mathrm{X}$ & $\mathrm{X}$ \\
\hline & & Cod & 2 & 3341 & 1.01 & 1.01 & $\mathrm{X}$ & $\mathrm{X}$ & $X$ & & & & $X$ & $\mathrm{X}$ \\
\hline & & Anglerfish & 2 & 4207 & 1.01 & 1.01 & $\mathrm{X}$ & $\mathrm{X}$ & $X$ & & $X$ & $\mathrm{X}$ & $X$ & $\mathrm{X}$ \\
\hline & & Saithe & 2 & 3170 & 1.01 & 1.01 & $\mathrm{X}$ & & $X$ & $X$ & & & $\mathrm{X}$ & \\
\hline & & R. Grenadier & 2 & 3064 & 1.01 & 1.01 & $\mathrm{X}$ & & $X$ & $\mathrm{X}$ & $X$ & $\mathrm{X}$ & $X$ & $\mathrm{X}$ \\
\hline & & Whiting & 2 & 2114 & 1.02 & 1.01 & $\mathrm{X}$ & & & $\mathrm{X}$ & & & $X$ & $\mathrm{X}$ \\
\hline \multirow[t]{4}{*}{ Netherlands } & FL13 & Plaice & 2 & 2960 & 1.00 & 1.00 & & & & & $\mathrm{X}$ & & $\mathrm{X}$ & \\
\hline & & Sole & 1 & 3338 & 1.06 & 0.93 & & & & & $\mathrm{X}$ & & & \\
\hline & FL14 & Plaice & 1 & 44108 & 1.06 & 1.04 & & & & & $X$ & & $X$ & \\
\hline & & Sole & 1 & 50012 & 1.06 & 1.01 & & & & & $\mathrm{X}$ & & $\mathrm{X}$ & \\
\hline \multirow[t]{4}{*}{ Spain } & FL15 & Hake & 1 & 2616 & 1.09 & 1.57 & & & & $\mathrm{X}$ & $\mathrm{X}$ & & $X$ & \\
\hline & FL16 & Hake & 1 & 3175 & 1.09 & 1.49 & & & & & & & $X$ & $\mathrm{X}$ \\
\hline & FL17 & Hake & 1 & 2618 & 1.09 & 1.26 & & & & $\mathrm{X}$ & $X$ & & & \\
\hline & & Anglerfish & 1 & 1715 & 1.08 & 1.52 & & & & $\mathrm{X}$ & $X$ & & $X$ & \\
\hline
\end{tabular}


Table 5. Outputs comparison of, (a) the no-intercept regression between fishing mortality (F) and nominal fishing effort (En) and, (b) the no-intercept regression between fishing mortality (F) and adjusted fishing effort (Ee). Species investigated are anglerfish (Lophius spp.), cod (Gadus morhua), haddock (Melanogrammus aeglefinus), hake (Merluccius merluccius), plaice (Pleuronectes platessa), saithe (Pollachius virens), sole (Solea solea), whiting (Merlangius merlangus). BB: Bay of Biscay, CS: Celtic Sea, North.: Northern, NS: North Sea, WS: Western Scotland.

\begin{tabular}{|c|c|c|c|c|c|}
\hline Fleet & Stock & $\mathrm{N}$ & $\mathrm{R}^{2}(\mathrm{a})$ & $\mathrm{R}^{2}$ (b) & Equation (b) \\
\hline \multirow[t]{3}{*}{ FL01 } & NS Cod & 1970 & 0.43 & 0.54 & $\mathrm{~F}=5.80 * 10^{-5} * \mathrm{Ee}$ \\
\hline & NS Plaice & 2200 & 0.35 & 0.49 & $\mathrm{~F}=1.43 * 10^{-7} * \mathrm{Ee}$ \\
\hline & NS Sole & 1279 & 0.40 & 0.50 & $\mathrm{~F}=1.19 * 10^{-4} * \mathrm{Ee}$ \\
\hline \multirow[t]{3}{*}{ FL02 } & NS Cod & 3003 & 0.37 & 0.49 & $\mathrm{~F}=4.29 * 10^{-5} * \mathrm{Ee}$ \\
\hline & NS Plaice & 2495 & 0.40 & 0.56 & $\mathrm{~F}=7.99 * 10^{-6} * \mathrm{Ee}$ \\
\hline & NS Sole & 1216 & 0.39 & 0.47 & $\mathrm{~F}=1.97 * 10^{-5} * \mathrm{Ee}$ \\
\hline \multirow[t]{3}{*}{ FL03 } & NS Cod & 1089 & 0.54 & 0.71 & $\mathrm{~F}=4.58 * 10^{-5} * \mathrm{Ee}$ \\
\hline & NS Plaice & 3346 & 0.24 & 0.56 & $\mathrm{~F}=5.58 * 10^{-6} * \mathrm{Ee}$ \\
\hline & NS Sole & 1972 & 0.35 & 0.48 & $\mathrm{~F}=1.11 * 10^{-5} * \mathrm{Ee}$ \\
\hline \multirow[t]{3}{*}{ FL04 } & NS Cod & 1093 & 0.52 & 0.71 & $\mathrm{~F}=3.25 * 10^{-5} * \mathrm{Ee}$ \\
\hline & NS Plaice & 1894 & 0.21 & 0.57 & $\mathrm{~F}=1.11 * 10^{-6} * \mathrm{Ee}$ \\
\hline & NS Sole & 1179 & 0.37 & 0.53 & $\mathrm{~F}=1.34 * 10^{-5} * \mathrm{Ee}$ \\
\hline \multirow[t]{2}{*}{ FL05 } & NS Cod & 184 & 0.21 & 0.27 & $\mathrm{~F}=3.15^{*} 10^{-5} * \mathrm{Ee}$ \\
\hline & NS Plaice & 316 & 0.44 & 0.62 & $\mathrm{~F}=1.21 * 10^{-5} * \mathrm{Ee}$ \\
\hline \multirow[t]{2}{*}{ FL06 } & NS Cod & 1521 & 0.29 & 0.34 & $\mathrm{~F}=2.06 * 10^{-5} * \mathrm{Ee}$ \\
\hline & NS Plaice & 1907 & 0.43 & 0.57 & $\mathrm{~F}=1.31 * 10^{-5} * \mathrm{Ee}$ \\
\hline FL07 & NS Cod & 1141 & 0.11 & 0.15 & $\mathrm{~F}=1.31 * 10^{-4} * \mathrm{Ee}$ \\
\hline
\end{tabular}




\begin{tabular}{|c|c|c|c|c|c|}
\hline & NS Plaice & 1656 & 0.57 & 0.65 & $\mathrm{~F}=1.05 * 10^{-6} * \mathrm{Ee}$ \\
\hline \multirow[t]{2}{*}{ FL08 } & NS Cod & 2008 & 0.13 & 0.20 & $\mathrm{~F}=1.29 * 10^{-5} * \mathrm{Ee}$ \\
\hline & NS Plaice & 2014 & 0.52 & 0.49 & $\mathrm{~F}=4.86 * 10^{-6} * \mathrm{E}$ \\
\hline \multirow[t]{2}{*}{ FL09 } & NS Cod & 45718 & 0.33 & 0.29 & $\mathrm{~F}=1.51 * 10^{-7} * \mathrm{E}$ \\
\hline & NS Haddock & 31984 & 0.20 & 0.41 & $\mathrm{~F}=2.40 * 10^{-7} * \mathrm{Ee}$ \\
\hline \multirow[t]{2}{*}{ FL10 } & NS Plaice & 8234 & 0.65 & 0.81 & $\mathrm{~F}=3.34 * 10^{-6} * \mathrm{E}$ \\
\hline & NS Sole & 4402 & 0.27 & 0.48 & $\mathrm{~F}=7.40 * 10^{-7} * \mathrm{Ee}$ \\
\hline FL11 & NS/WS Saithe & 854 & 0.64 & 0.62 & $\mathrm{~F}=1.69 * 10^{-3} * \mathrm{Ee}$ \\
\hline \multirow[t]{5}{*}{ FL12 } & CS Cod & 2102 & 0.27 & 0.29 & $\mathrm{~F}=2.06 * 10^{-6} * \mathrm{Ee}$ \\
\hline & CS Whiting & 2241 & 0.21 & 0.38 & $\mathrm{~F}=5.02 * 10^{-5} * \mathrm{Ee}$ \\
\hline & CS/BB Anglerfish & 2711 & 0.23 & 0.27 & $\mathrm{~F}=4.37 * 10^{-6} * \mathrm{Ee}$ \\
\hline & NS/WS Anglerfish & 2096 & 0.36 & 0.44 & $\mathrm{~F}=6.13^{*} 10^{-5} * \mathrm{Ee}$ \\
\hline & NS/WS Saithe & 1731 & 0.26 & 0.23 & $\mathrm{~F}=1.55 * 10^{-8} * \mathrm{E}$ \\
\hline \multirow[t]{2}{*}{ FL13 } & NS Plaice & 3111 & 0.73 & 0.75 & $\mathrm{~F}=3.55^{*} 10^{-5} * \mathrm{Ee}$ \\
\hline & NS Sole & 3500 & 0.70 & 0.73 & $\mathrm{~F}=7.01 * 10^{-5} * \mathrm{E}$ \\
\hline \multirow[t]{2}{*}{ FL14 } & NS Plaice & 46270 & 0.73 & 0.74 & $\mathrm{~F}=2.55^{*} 10^{-5} * \mathrm{Ee}$ \\
\hline & NS Sole & 52179 & 0.70 & 0.73 & $\mathrm{~F}=5.38 * 10^{-5} * \mathrm{E}$ \\
\hline FL15 & North. Hake & 2646 & 0.34 & 0.60 & $\mathrm{~F}=1.43 * 10^{-8} * \mathrm{Ee}$ \\
\hline FL16 & North. Hake & 3237 & 0.37 & 0.67 & $\mathrm{~F}=2.45^{*} 10^{-7} * \mathrm{Ee}$ \\
\hline \multirow[t]{2}{*}{ FL17 } & North. Hake & 2685 & 0.60 & 0.66 & $\mathrm{~F}=2.31 * 10^{-7} * \mathrm{Ee}$ \\
\hline & BB/CS Anglerfish & 1778 & 0.46 & 0.46 & $\mathrm{~F}=4.05^{*} 10^{-9} * \mathrm{Ee}$ \\
\hline
\end{tabular}


Table 6. Outputs comparison of, (a) the regression between Log fishing mortality (LF) and Log nominal fishing effort (Len) and, (b) the regression between Log fishing mortality (LF) and Log adjusted fishing effort (LEe). The standard error of the slope of regression (b) is indicated, and marked with a “*” when the slope is significantly different from $1(\mathrm{p}<0.05)$. Species investigated are anglerfish (Lophius spp.), cod (Gadus morhua), haddock (Melanogrammus aeglefinus), hake (Merluccius merluccius), plaice (Pleuronectes platessa), saithe (Pollachius virens), sole (Solea solea), whiting (Merlangius merlangus). BB: Bay of Biscay, CS: Celtic Sea, North.: Northern, NS: North Sea, WS: Western Scotland.

\begin{tabular}{|c|c|c|c|c|c|c|}
\hline Fleet & Stock & $\mathrm{N}$ & $\begin{array}{l}\mathrm{R}^{2} \\
\text { (a) }\end{array}$ & $\begin{array}{l}\mathrm{R}^{2} \\
\text { (b) }\end{array}$ & $\begin{array}{l}\text { Standard error } \\
\text { of slope (b) }\end{array}$ & Equation (b) \\
\hline \multirow[t]{3}{*}{ FL01 } & NS Cod & 1970 & 0.13 & 0.59 & 0.02 & $\mathrm{LF}=-10.01+1.00 * \mathrm{LEe}$ \\
\hline & NS Plaice & 2200 & 0.05 & 0.53 & 0.02 & $\mathrm{LF}=-12.05+0.96 * \mathrm{LEe}$ \\
\hline & NS Sole & 1279 & 0.03 & 0.34 & $0.04 *$ & $\mathrm{LF}=-9.31+0.90 * \mathrm{LEe}$ \\
\hline \multirow[t]{3}{*}{ FL02 } & NS Cod & 3003 & 0.13 & 0.53 & $0.02 *$ & $\mathrm{LF}=-10.03+0.95 * \mathrm{LEe}$ \\
\hline & NS Plaice & 2495 & 0.11 & 0.41 & 0.02 & $\mathrm{LF}=-12.25+0.99 * \mathrm{LEe}$ \\
\hline & NS Sole & 1216 & 0.14 & 0.47 & 0.03 & $\mathrm{LF}=-10.86+0.97 * \mathrm{LEe}$ \\
\hline \multirow[t]{3}{*}{ FL03 } & NS Cod & 1089 & 0.08 & 0.45 & $0.03 *$ & $\mathrm{LF}=-10.00+0.83 * \mathrm{LEe}$ \\
\hline & NS Plaice & 3346 & 0.14 & 0.53 & $0.02 *$ & $\mathrm{LF}=-12.13+0.93 * \mathrm{LEe}$ \\
\hline & NS Sole & 1972 & 0.10 & 0.48 & $0.02 *$ & $\mathrm{LF}=-11.19+0.83 * \mathrm{LEe}$ \\
\hline \multirow[t]{3}{*}{ FL04 } & NS Cod & 1093 & 0.05 & 0.37 & 0.04 & $\mathrm{LF}=-10.49+0.95 * \mathrm{LEe}$ \\
\hline & NS Plaice & 1894 & 0.17 & 0.67 & 0.02 & $\mathrm{LF}=-13.76+0.98 * \mathrm{LEe}$ \\
\hline & NS Sole & 1179 & 0.08 & 0.49 & $0.03^{*}$ & $\mathrm{LF}=-11.10+0.88 * \mathrm{LEe}$ \\
\hline \multirow[t]{2}{*}{ FL05 } & NS Cod & 184 & 0.07 & 0.06 & $0.13^{*}$ & $\mathrm{LF}=-10.37+0.46^{*} \mathrm{LEe}$ \\
\hline & NS Plaice & 316 & 0.30 & 0.44 & $0.09 *$ & $\mathrm{LF}=-12.99+1.44 * \mathrm{LEe}$ \\
\hline FL06 & NS Cod & 1521 & 0.03 & 0.04 & $0.05^{*}$ & $\mathrm{LF}=-10.06+0.35 * \mathrm{LEe}$ \\
\hline
\end{tabular}




\begin{tabular}{|c|c|c|c|c|c|c|}
\hline & NS Plaice & 1907 & 0.31 & 0.39 & $0.04^{*}$ & $\mathrm{LF}=-12.99+1.42 * \mathrm{LEe}$ \\
\hline \multirow[t]{2}{*}{ FL07 } & NS Cod & 1141 & 0.03 & 0.11 & $0.05^{*}$ & $\mathrm{LF}=-9.83+0.61 * \mathrm{LEe}$ \\
\hline & NS Plaice & 1656 & 0.23 & 0.36 & $0.03^{*}$ & $\mathrm{LF}=-14.36+1.08 * \mathrm{LEe}$ \\
\hline \multirow[t]{2}{*}{ FL08 } & NS Cod & 2008 & 0.02 & 0.10 & $0.04 *$ & $\mathrm{LF}=-11.17+0.59 * \mathrm{LEe}$ \\
\hline & NS Plaice & 2014 & 0.34 & 0.49 & 0.02 & $\mathrm{LF}=-12.13+1.02 * \mathrm{LEe}$ \\
\hline \multirow[t]{2}{*}{ FL09 } & NS Cod & 45718 & 0.31 & 0.58 & $0.00 *$ & $\mathrm{LF}=-14.79+0.99 * \mathrm{LEe}$ \\
\hline & NS Haddock & 31984 & 0.30 & 0.48 & $0.01^{*}$ & $\mathrm{LF}=-15.02+1.02 * \mathrm{LEe}$ \\
\hline \multirow[t]{2}{*}{ FL10 } & NS Plaice & 8234 & 0.16 & 0.30 & $0.01^{*}$ & $\mathrm{LF}=-12.01+0.77 * \mathrm{LEe}$ \\
\hline & NS Sole & 4402 & 0.03 & 0.36 & $0.02 *$ & $\mathrm{LF}=-13.97+0.88 * \mathrm{LEe}$ \\
\hline FL11 & NS/WS Saithe & 854 & 0.28 & 0.69 & $0.02 *$ & $\mathrm{LF}=-6.34+0.95 * \mathrm{LEe}$ \\
\hline \multirow[t]{5}{*}{ FL12 } & CS Cod & 2102 & 0.17 & 0.23 & $0.02 *$ & $\mathrm{LF}=-11.50+0.54 * \mathrm{LEe}$ \\
\hline & CS Whiting & 2241 & 0.07 & 0.23 & $0.02 *$ & $\mathrm{LF}=-10.36+0.61 * \mathrm{LEe}$ \\
\hline & CS/BB Anglerfish & 2711 & 0.12 & 0.15 & $0.02 *$ & $\mathrm{LF}=-12.74+0.48 * \mathrm{LEe}$ \\
\hline & NS/WS Anglerfish & 2096 & 0.04 & 0.16 & 0.05 & $\mathrm{LF}=-10.38+0.99 * \mathrm{LEe}$ \\
\hline & NS/WS Saithe & 1731 & 0.00 & 0.05 & $0.05^{*}$ & $\mathrm{LF}=-14.81+0.46^{*} \mathrm{LEe}$ \\
\hline \multirow[t]{2}{*}{ FL13 } & NS Plaice & 3111 & 0.26 & 0.29 & 0.03 & $\mathrm{LF}=-10.45+1.01 * \mathrm{LEe}$ \\
\hline & NS Sole & 3500 & 0.12 & 0.24 & 0.03 & $\mathrm{LF}=-9.71+0.95 * \mathrm{LEe}$ \\
\hline \multirow[t]{2}{*}{ FL14 } & NS Plaice & 46270 & 0.32 & 0.34 & $0.01 *$ & $\mathrm{LF}=-10.87+1.07 * \mathrm{LEe}$ \\
\hline & NS Sole & 52179 & 0.16 & 0.30 & 0.01 & $\mathrm{LF}=-10.00+1.01 * \mathrm{LEe}$ \\
\hline FL15 & North. Hake & 2646 & 0.05 & 0.66 & $0.01^{*}$ & $\mathrm{LF}=-18.04+0.96 * \mathrm{LEe}$ \\
\hline FL16 & North. Hake & 3237 & 0.10 & 0.52 & $0.02 *$ & $\mathrm{LF}=-15.24+0.94 * \mathrm{LEe}$ \\
\hline \multirow[t]{2}{*}{ FL17 } & North. Hake & 2685 & 0.09 & 0.20 & 0.03 & $\mathrm{LF}=-14.07+0.72 * \mathrm{LEe}$ \\
\hline & BB/CS Anglerfish & 1778 & 0.25 & 0.38 & $0.02 *$ & $\mathrm{LF}=-17.32+0.69 * \mathrm{LEe}$ \\
\hline
\end{tabular}




\section{Figure captions}

Figure 1. Map of the fishing areas of the International Council for the Exploration of the Sea (ICES).

Figure 2. Average value and standard deviation of the indices of fishing tactics and fishing strategies, sorted in ascending order, for the fleets under investigation; (a) FT_SW, (b) YE_SW, (c) FT_DIST, (d) YE_DIST, (e) FT_PATCH, (f) YE_PATCH, (g) YE_IAC, (h) YE_SW_METIER.

Figure 3. Pearson correlation coefficients calculated between (a) FT_SW, (b) FT_DIST, (c) FT_PATCH, (d) YE_SW, (e) YE_DIST, (f) YE_PATCH, (g) YE_SW_METIER, (h) YE_IAC and the other indices of fishing tactics and strategies for all the fleets under investigation.

Figure 4. Effects of the different métiers, as derived from the Generalized Linear Models. Danish fleets (FL01-FL08) harvesting cod (Gadus morhua), white pattern; plaice (Pleuronectes platessa), black pattern; and sole (Solea solea), grey pattern.

Figure 5. Effects of the different métiers, as derived from the Generalized Linear Models. English and French fleets (FL09-FL12) harvesting anglerfish (Lophius spp.), black scabbard (Aphanopus carbo), blue ling (Molva dypterigia), cod (Gadus morhua), haddock (Melanogrammus aeglefinus), plaice (Pleuronectes platessa), roundnose grenadier (Coryphaenoides rupestris), saithe (Pollachius virens), sole (Solea solea), whiting (Merlangius merlangus).

Figure 6. Effects of the different métiers, as derived from the Generalized Linear Models. Dutch and Basque fleets (FL13-FL17) harvesting (gray shading) anglerfish (Lophius spp.), (hatching) hake (Merluccius merluccius), (white) plaice (Pleuronectes platessa), (black) sole (Solea solea). 
Figure 7. Effects of the indices of fishing tactics FT_SW (a), FT_DIST (c) and strategies YE_SW (b), YE_DIST (d), as derived from the Generalized Linear Models, for the different combinations of fleets and species. BLI: blue ling (Molva dypterigia), BSF: black scabbard (Aphanopus carbo), COD: cod (Gadus morhua), HAD: haddock (Melanogrammus aeglefinus), HKE: hake (Merluccius merluccius), MNZ: anglerfish (Lophius spp.), PLE: plaice (Pleuronectes platessa), POK: saithe (Pollachius virens), SOL: sole (Solea solea), WHG: Whiting (Merlangius merlangus).

Figure 8. Effects of the indices of fishing tactics FT_PATCH (a) and strategies YE_PATCH (b), YE_SW_METIER (c), YE_IAC (d), as derived from the Generalized Linear Models, for the different combinations of fleets and species. BLI: blue ling (Molva dypterigia), BSF: black scabbard (Aphanopus carbo), COD: cod (Gadus morhua), HAD: haddock (Melanogrammus aeglefinus), HKE: hake (Merluccius merluccius), MNZ: anglerfish (Lophius spp.), PLE: plaice (Pleuronectes platessa), POK: saithe (Pollachius virens), SOL: sole (Solea solea), WHG: whiting (Merlangius merlangus).

Figure 9. Relationships between log-transformed catch per unit effort (CPUE) and fishing power by métier, as derived from the Generalized Linear Models. Fleets FL04 harvesting plaice (Pleuronectes platessa) (a) and sole (Solea solea) (b), FL09 harvesting cod (Gadus morhua) (c), FL10 harvesting sole (d), FL11 harvesting saithe (Pollachius virens) (e), FL15 harvesting hake (Merluccius merluccius) (f).

Figure 10. Relationships between log-transformed; (a, c, d, g) partial fishing mortality, $\log (\mathrm{F})$, and nominal fishing effort, $\log (\mathrm{En})$; (b, d, f, h) partial fishing mortality, $\log (\mathrm{F})$, and adjusted fishing effort, Log(Ee). Fleets FL04 harvesting North Sea plaice (Pleuronectes platessa) (a, b) and sole (Solea solea) (c, d); FL08 harvesting North Sea plaice (Pleuronectes platessa) (e, f) and sole (Solea solea) (g, h). 
Figure 11. Relationships between log-transformed; (a, c, d, g) partial fishing mortality, $\log (\mathrm{F})$, and nominal fishing effort, $\log (\mathrm{En})$; (b, d, f, h) partial fishing mortality, $\log (\mathrm{F})$, and adjusted fishing effort, $\log (\mathrm{Ee})$. Fleets FL09 harvesting North Sea cod (Gadus morhua) (a, b), FL11 harvesting North Sea and Western Scotland saithe (Pollachius virens) (c, d), FL15 harvesting northern hake (Merluccius merluccius) (e, f). 


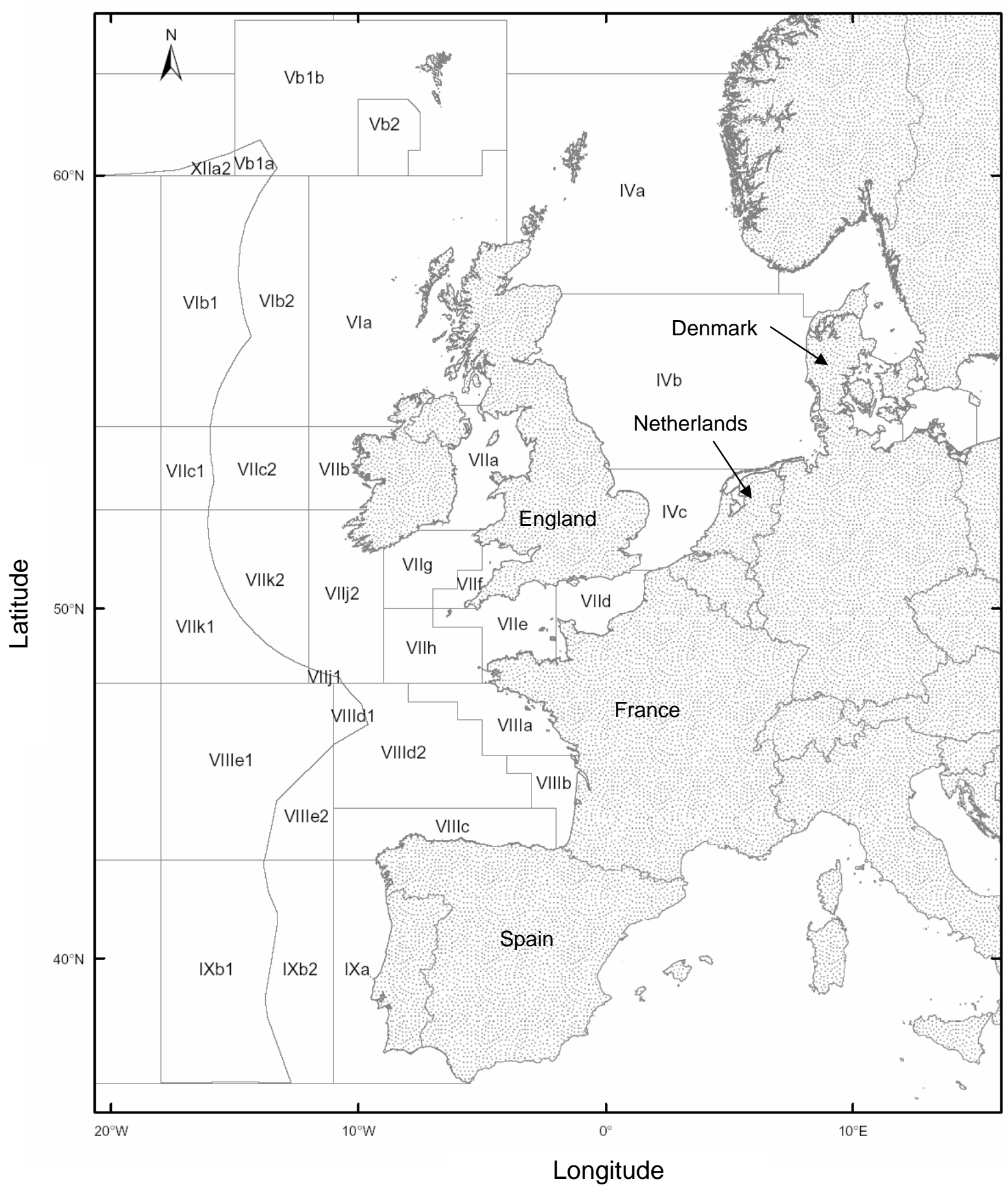



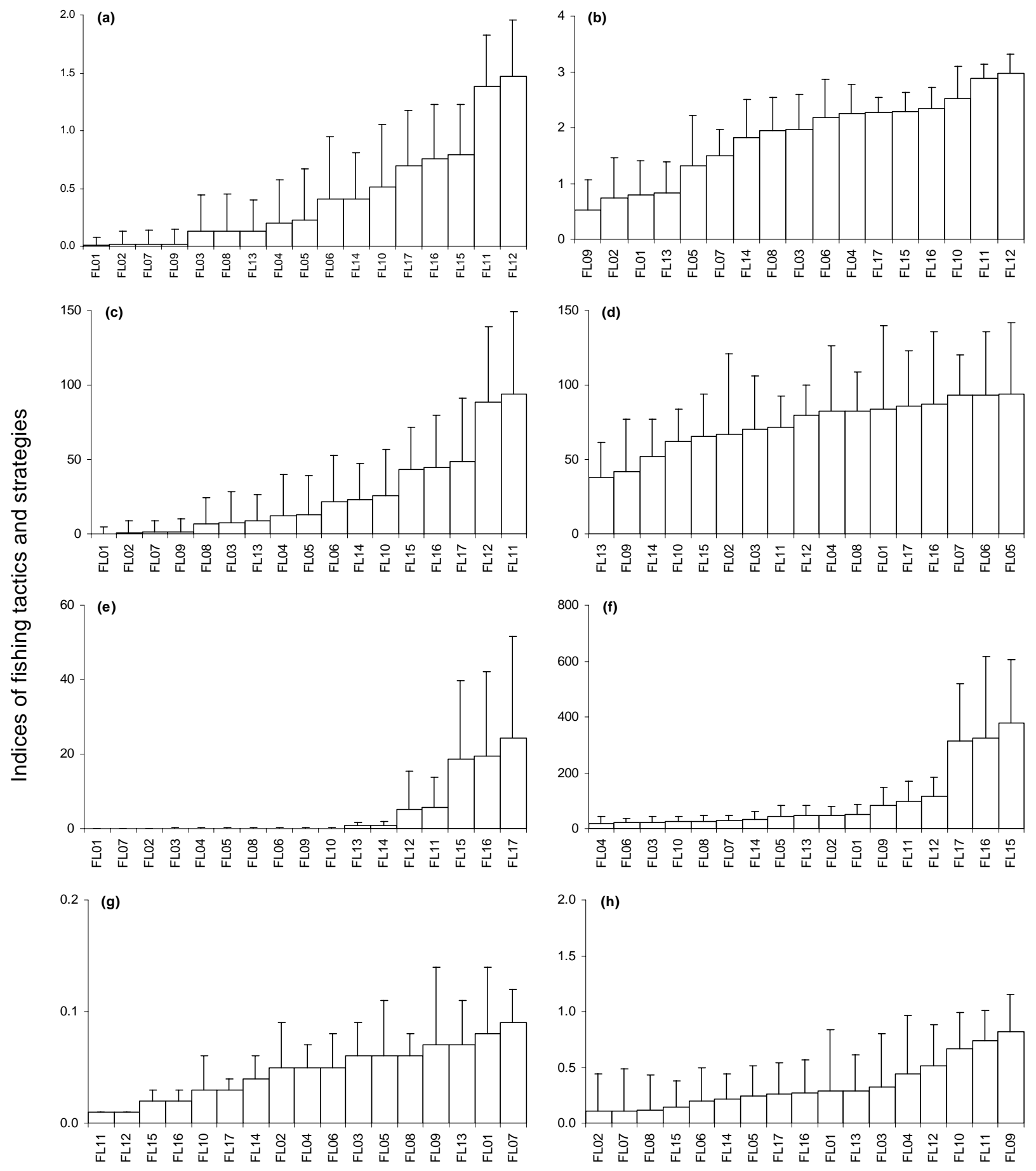

Fleets 


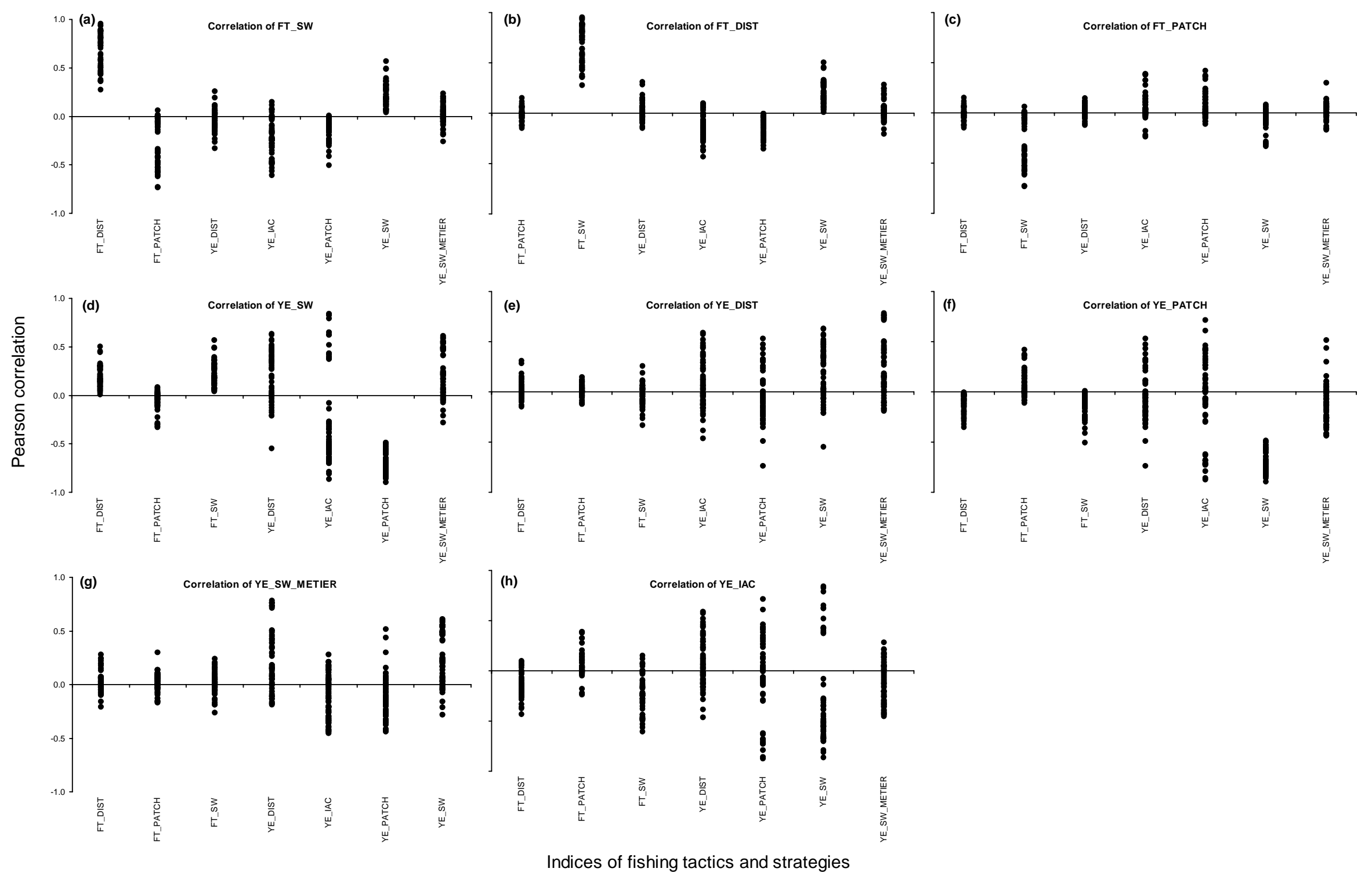




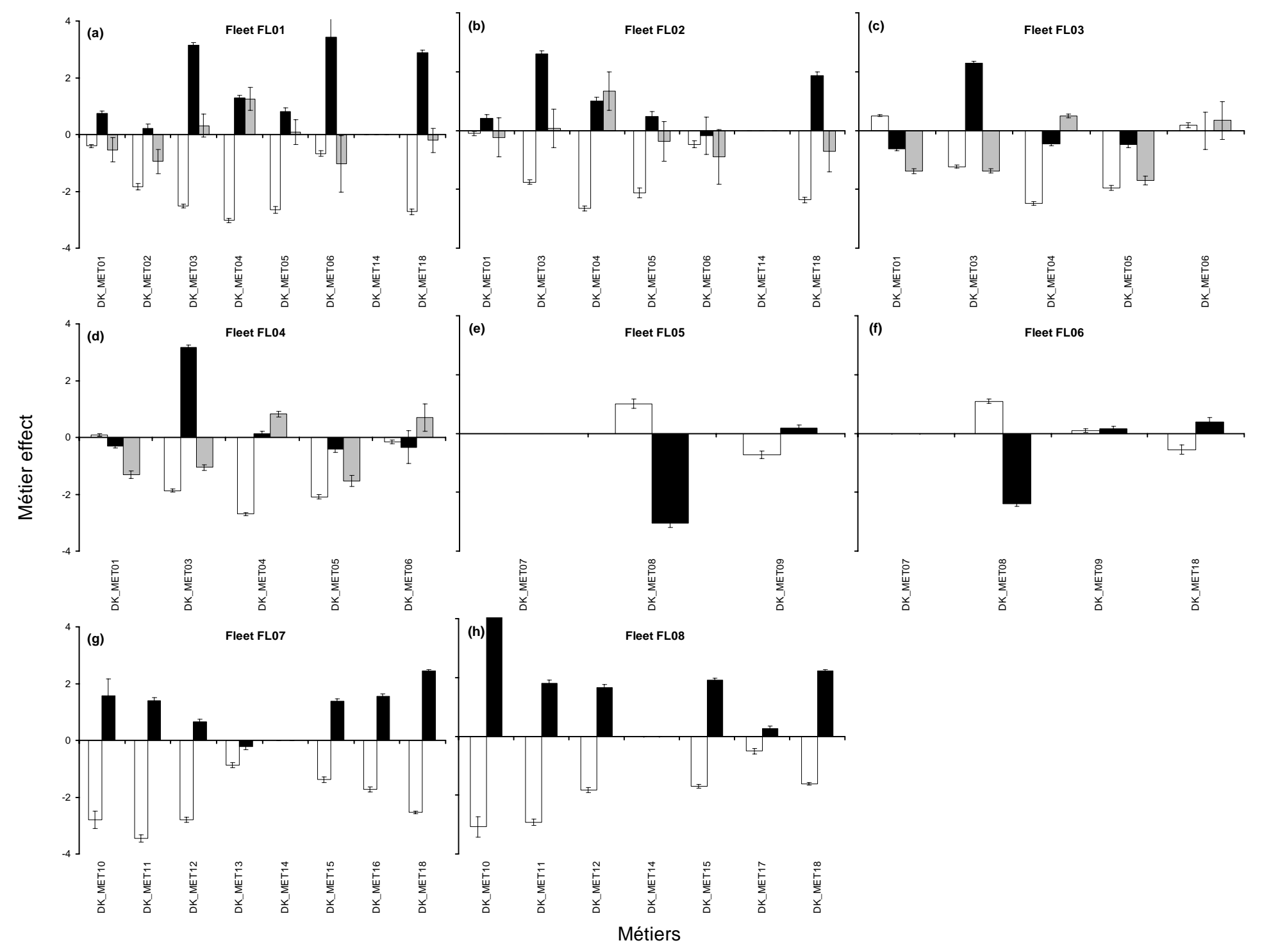




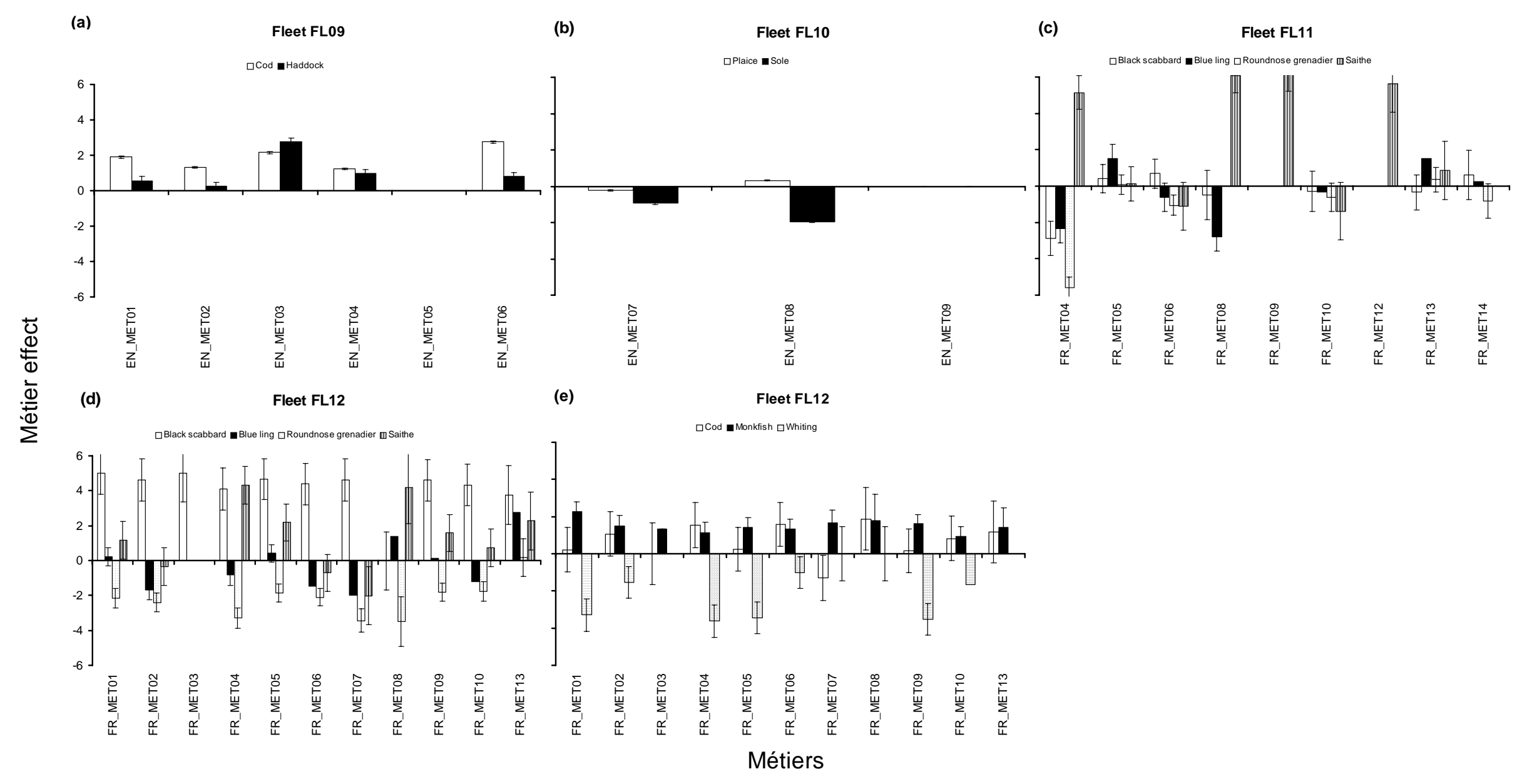




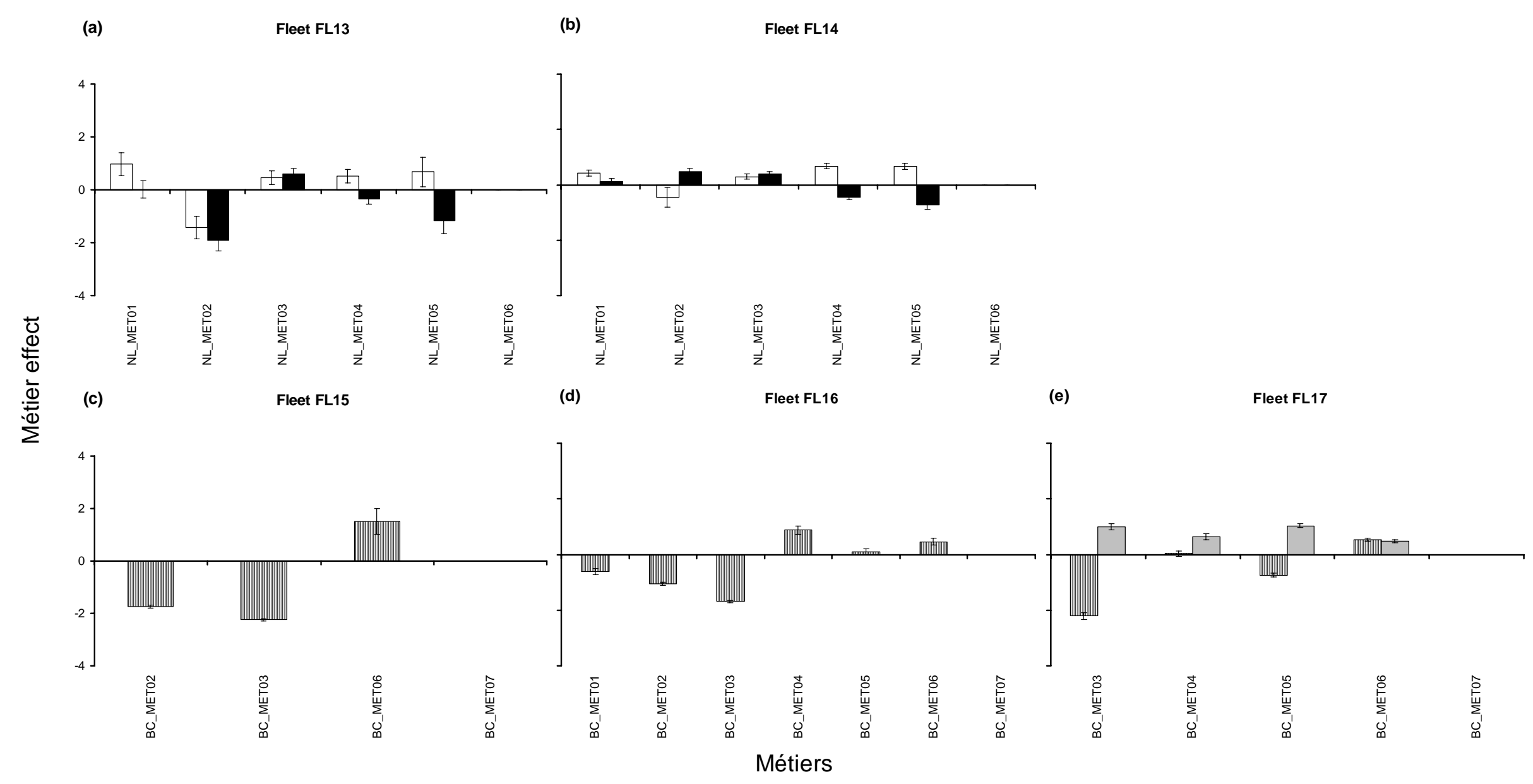




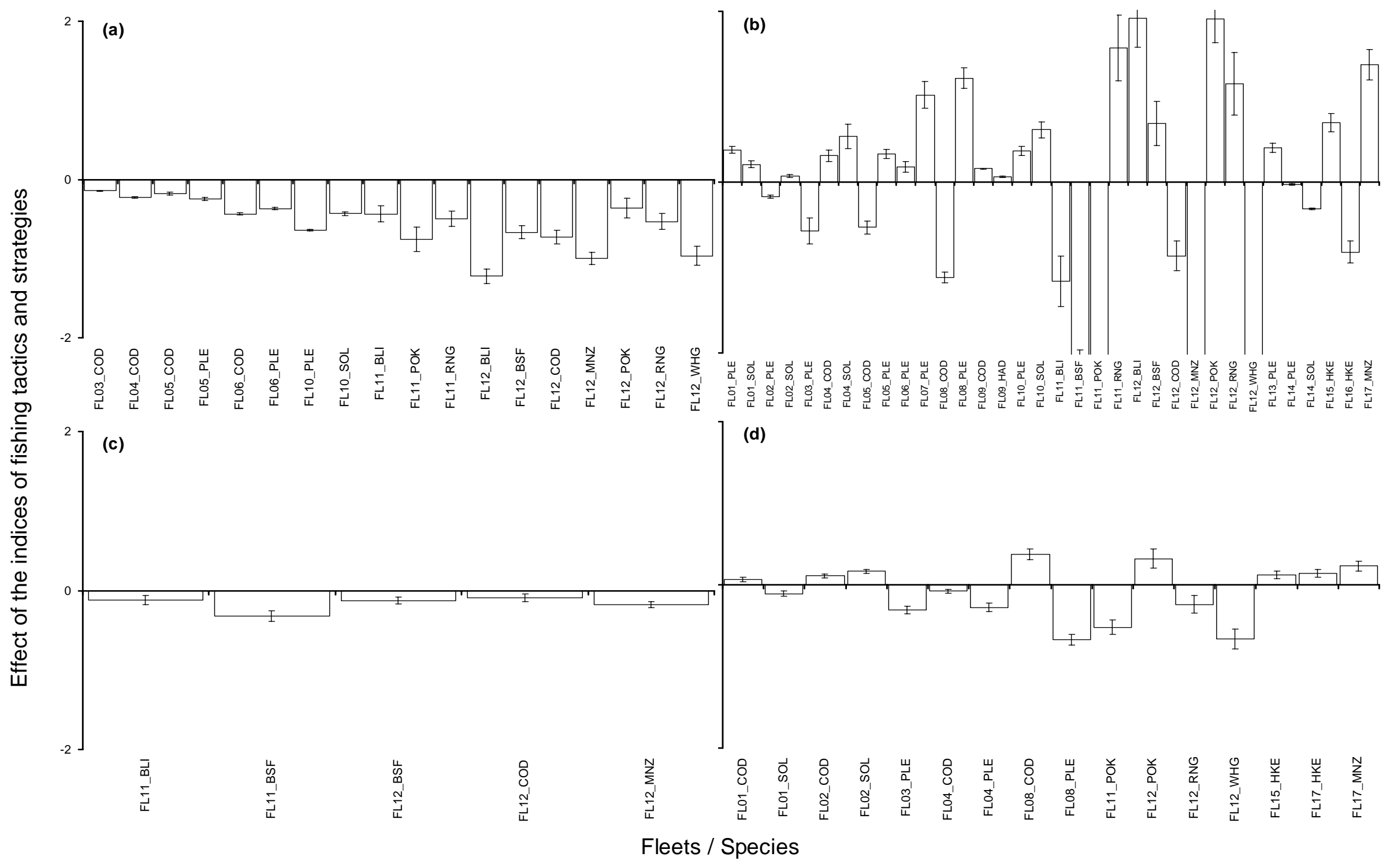




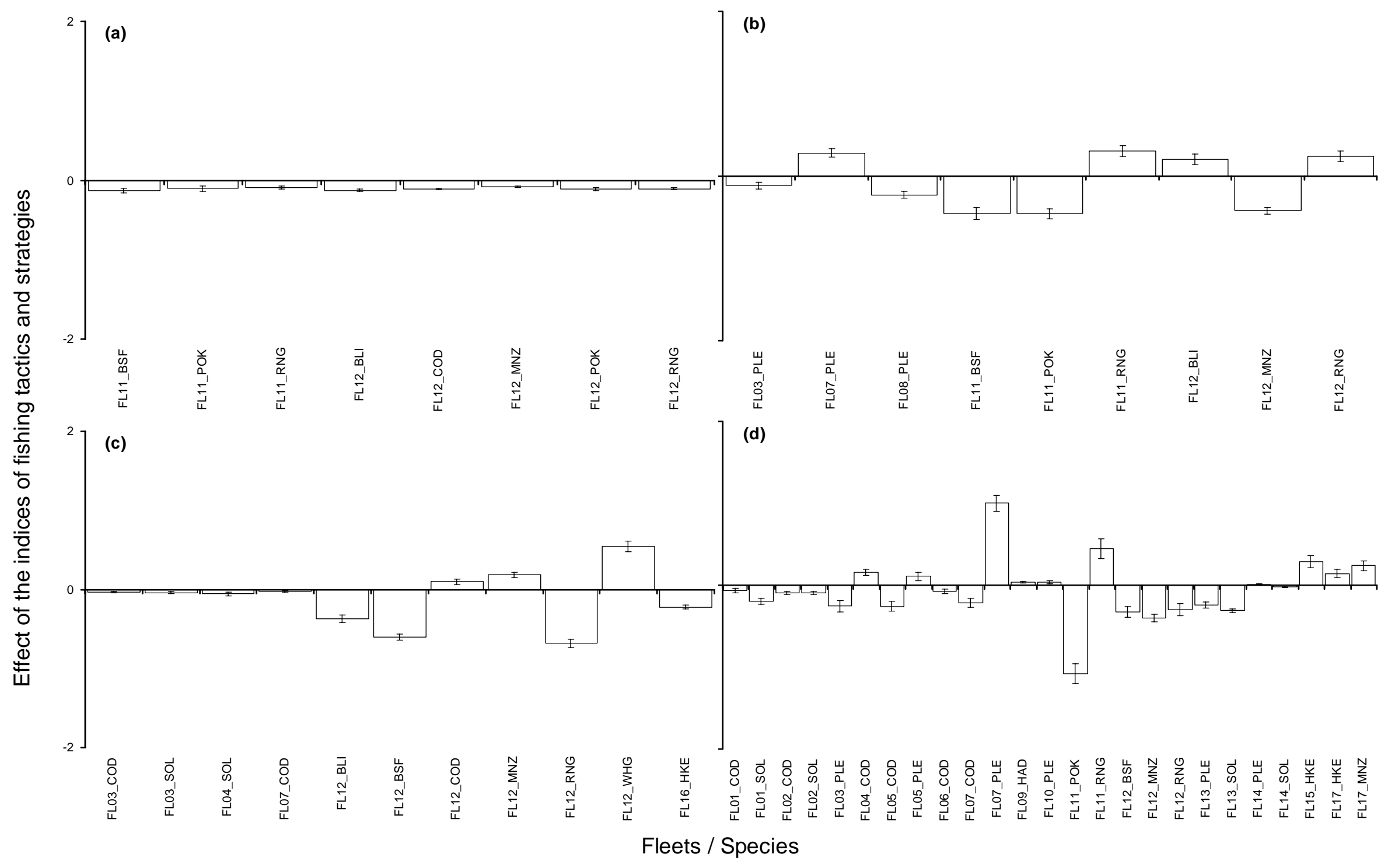



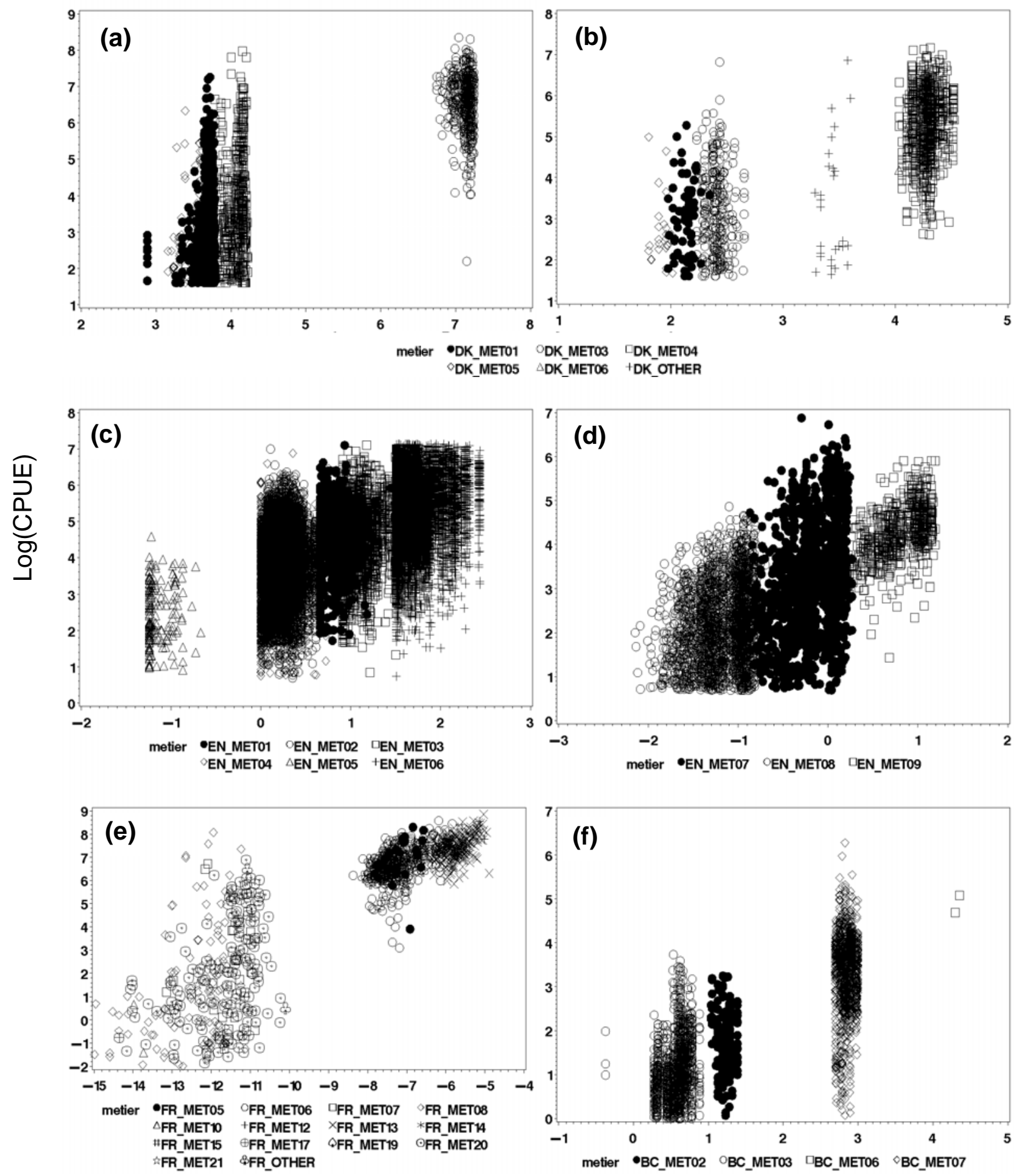

Log(Fishing power) 

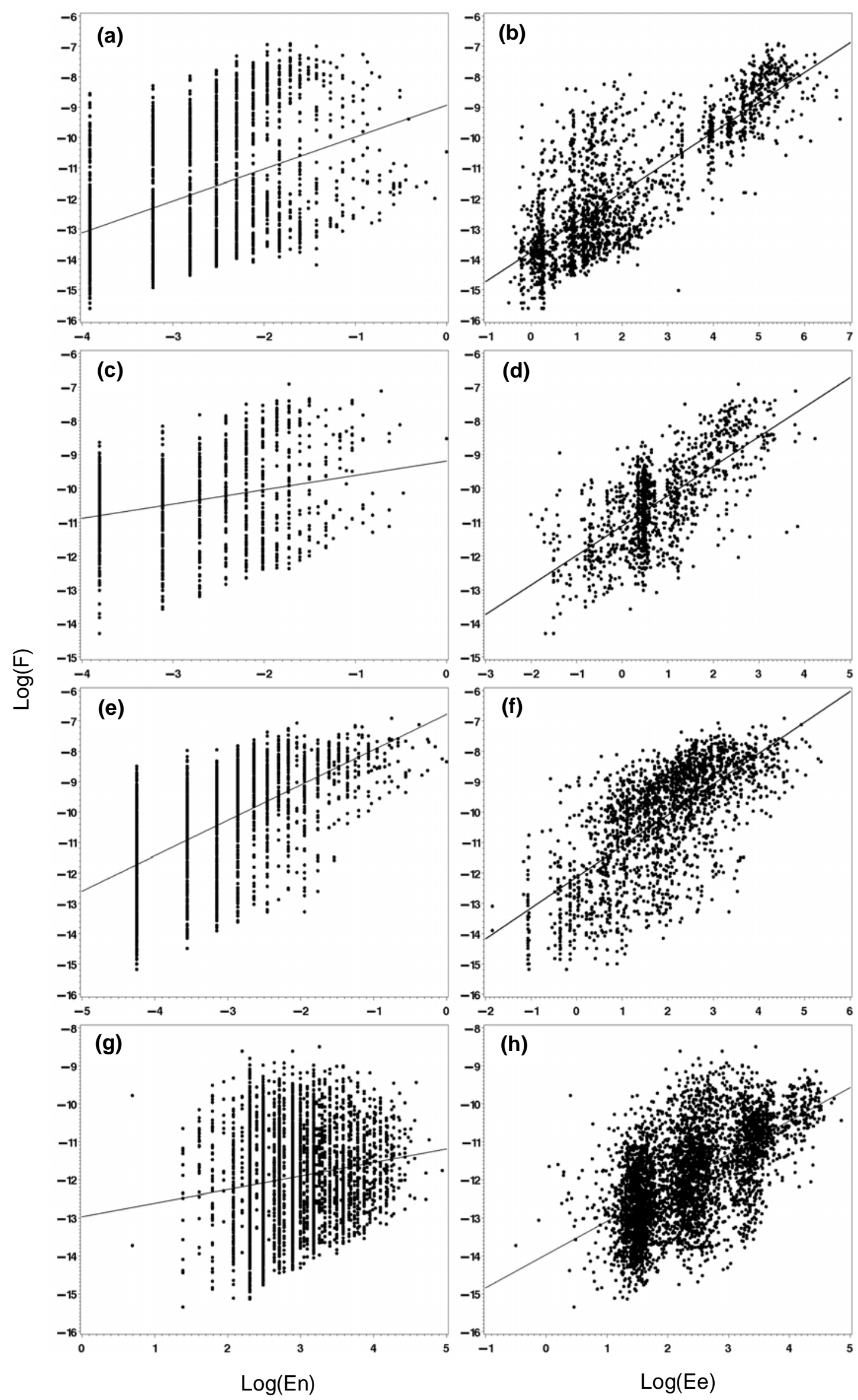

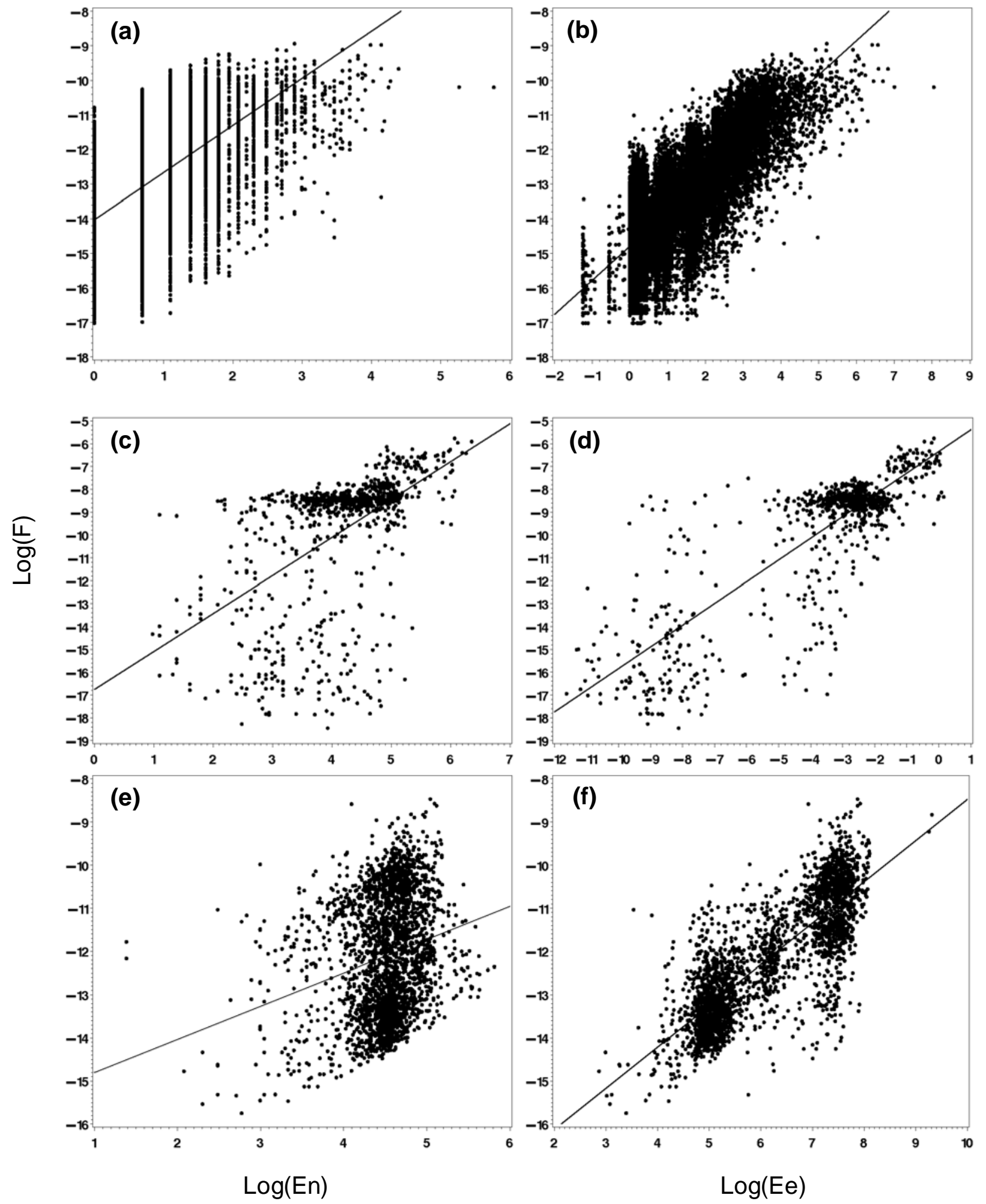